استر اتيجية قائمة على التعلم النشط لتنمية مهار ات البر هان الرياضي لاى تلاميذ المرحلة المتوسطة بدولة الكويت

أ.م.د/ محمد حاجى على خاجه** - ( )

* أستاذ مساعد دكتور بقسم المناهج وطرق التدريس بكلية التربية الأساسية، ورئيس مكتب التربية العملية، بالهيئة

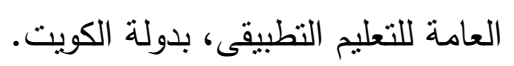




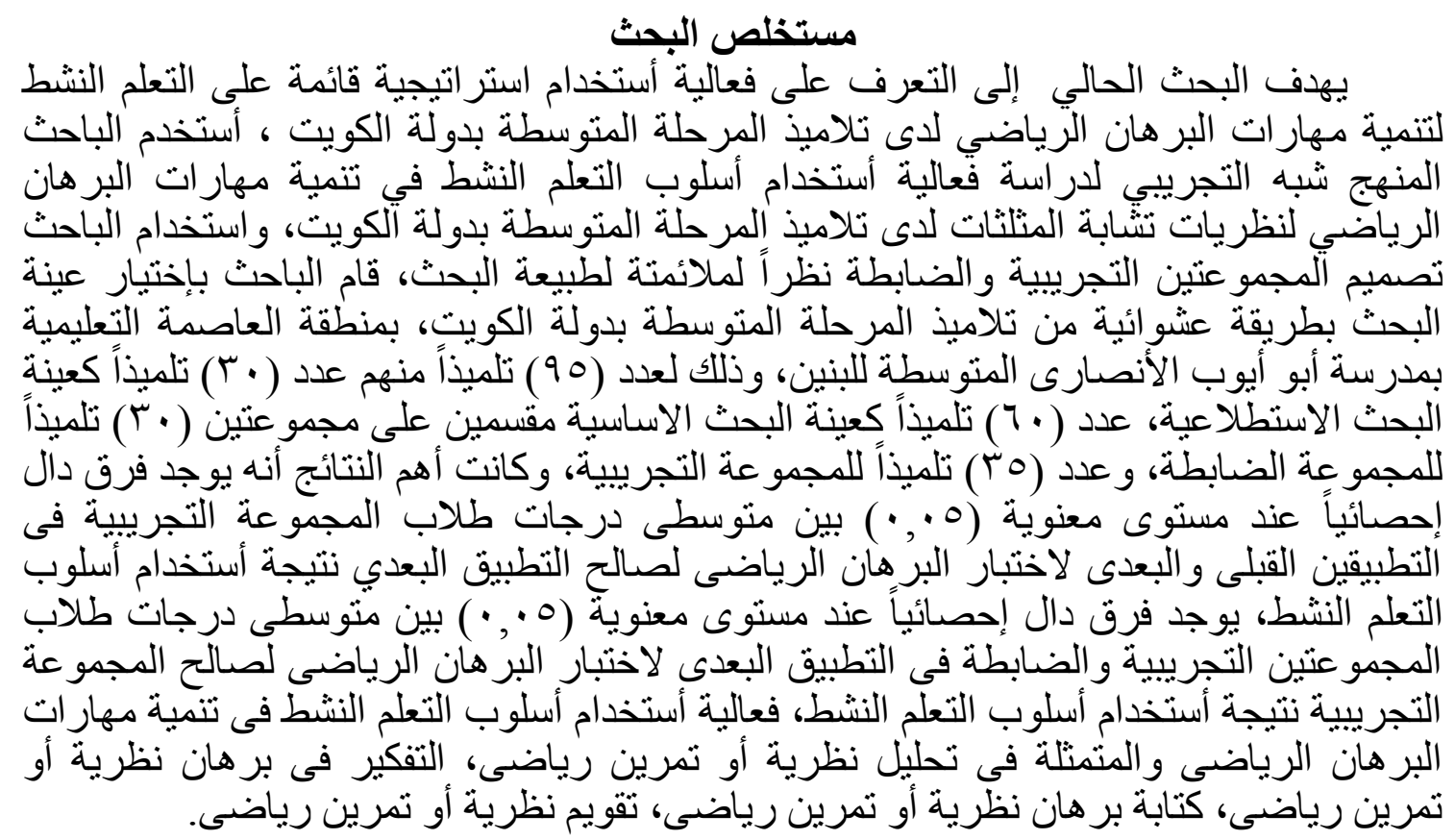

A strategy based on active learning to develop mathematical proof skills among middle school students in Kuwait

Mohamed Haji Ali Khajah *

\section{Abstract of Research}

The research aims current to identify a strategy based on active learning to develop mathematical proof skills among middle school students in Kuwait, researcher used the experimental method to study the effectiveness of using a method of active learning in the development of skills mathematical proof for the theories of similarity triangles stage pupils medium in Kuwait, and the use Researcher design experimental and control groups because of its relevance to the nature of the research, the researcher to choose the sample randomly from pupils intermediate stage in Kuwait, the capital region educational school Abu Ayyub al-Ansari medium for boys, and for a number (95) pupils whom number (30) pupils sample search exploratory, number (60) pupils sample search core divided into two groups (30) a disciple of the control group, and the number (35) students of the experimental group, and the most important results that are statistically significant differences at the abstract level (0.05) between the mean scores students the experimental group in two applications pre and post test mathematical proof in theories similarity triangles favor of the post due to the use method of active learning, no statistically significant

\footnotetext{
* Associate t Professor Department of Curriculums \& teaching Methods, Faculty of Basic Education, Head of the Bureau of Education process, the Public Authority for Applied Education, Kuwait.
} 
differences at the abstract level (0.05) between the mean scores students experimental and control groups in the post to test mathematical proof in theories similarity triangles for the experimental group due to the use active learning method, the effective use of the active learning method in the development of mathematical proof and skills represented in the analysis of the theory or pushup, thinking in proof theory or pushup, written proof theory or pushup, calendar theory or pushup.

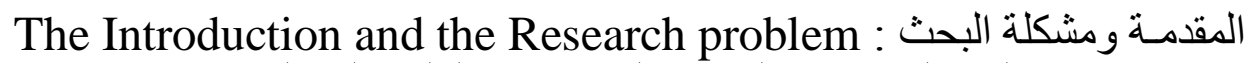

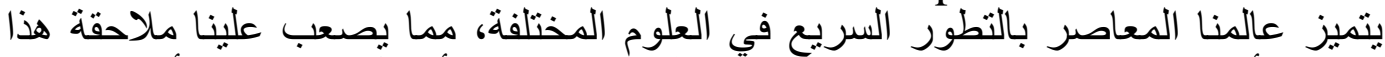
التطور بإتباع أساليب التدريس العادية، ولذا ينبغي علينيا الينا البحث عن أفضل الطرق والأساليب التي

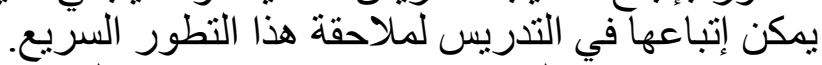

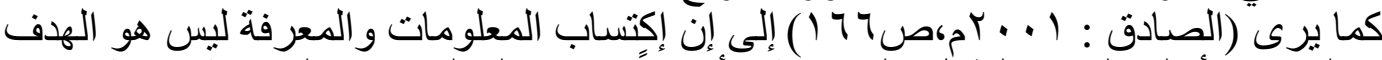

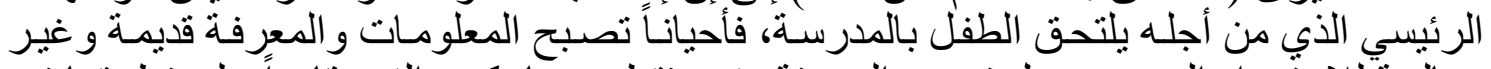

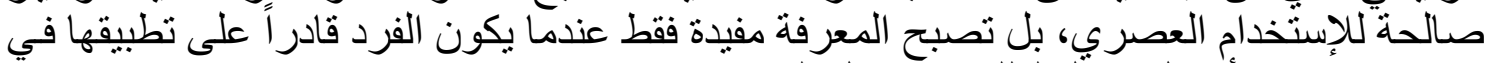

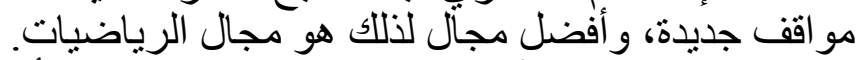

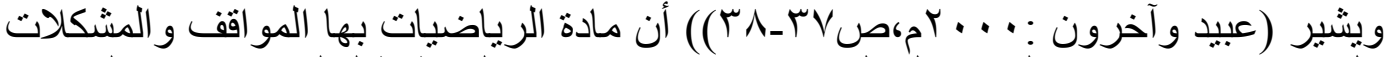

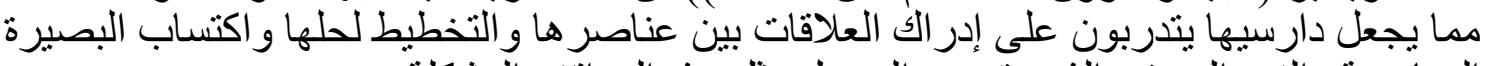

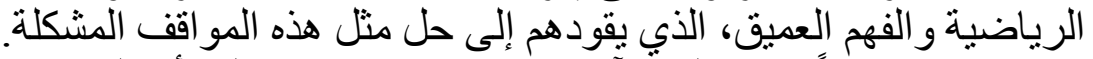

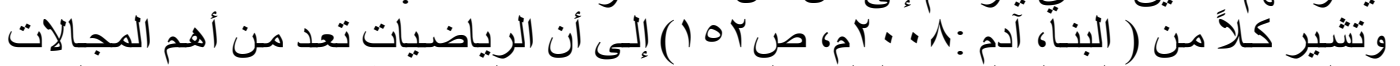

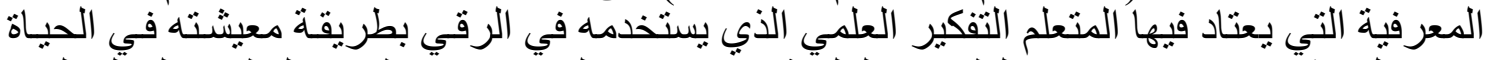

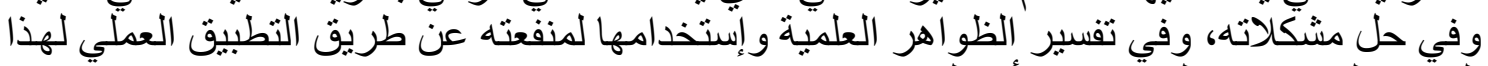
التفكير الذي تعتبر الرياضضيات أداة له.

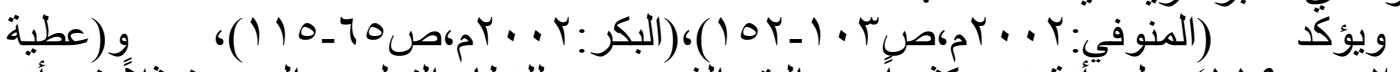

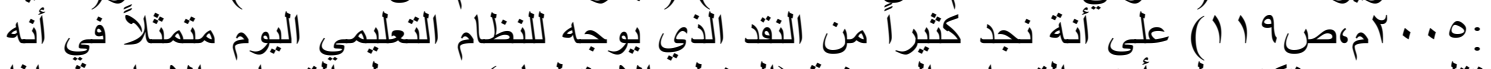

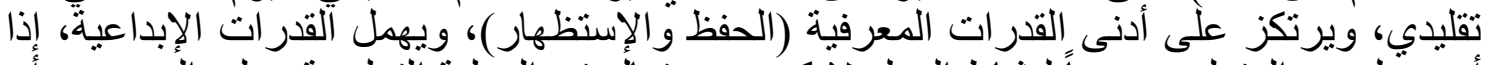

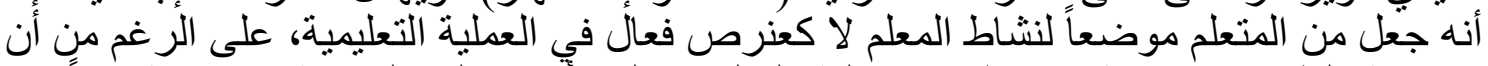

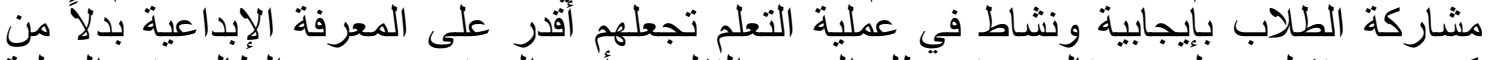

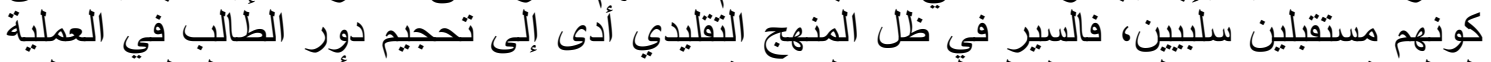

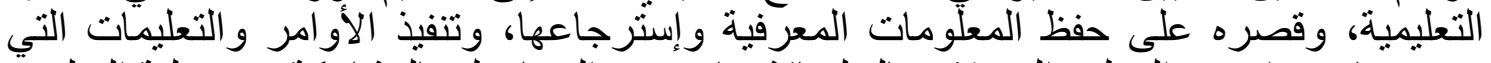

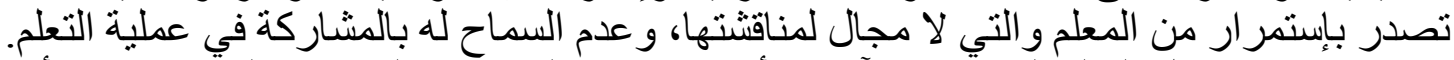

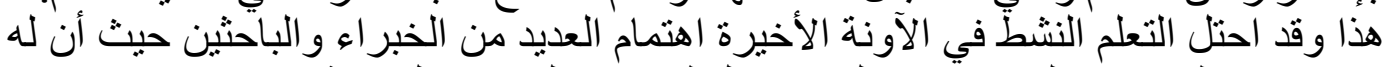

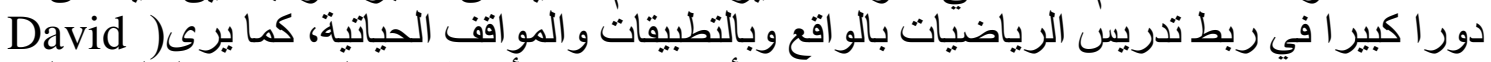

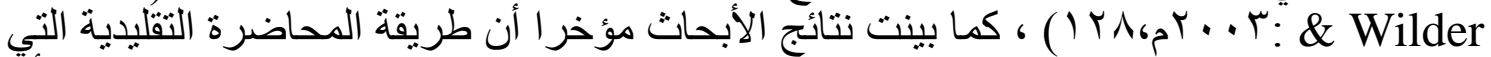

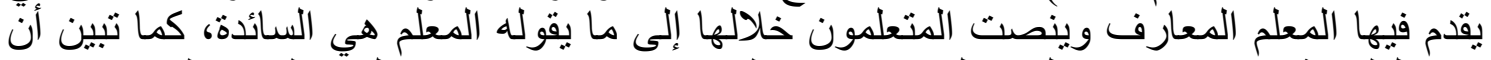

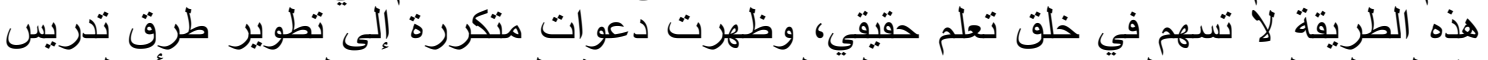

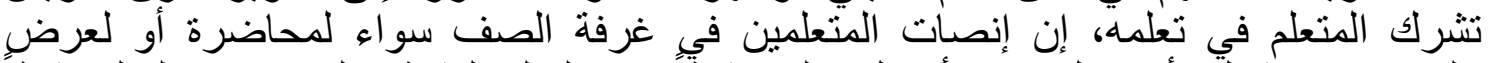

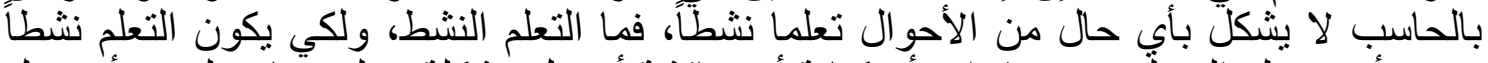

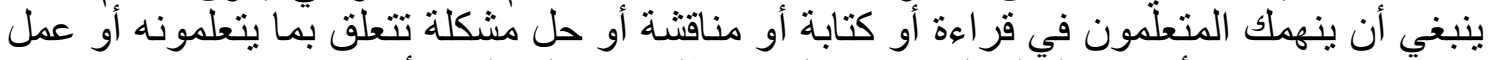

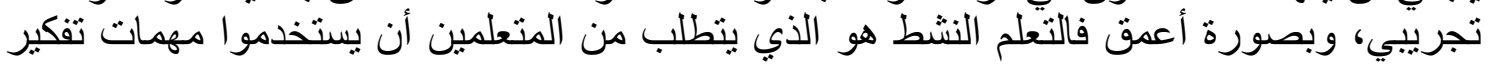


عليا كالتحليل و التركيب و التقويم فيما يتعلق بما يتعلمونه، وبناء على ما سبق فإن التعلم النشط هو

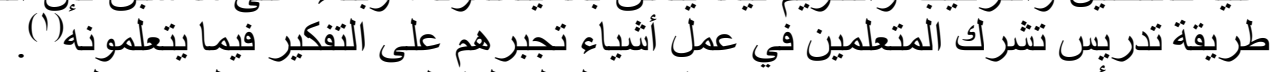

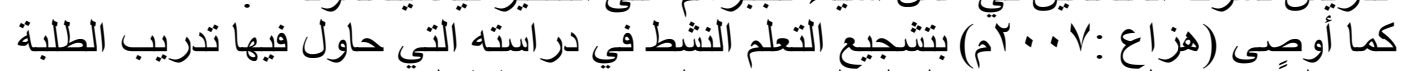

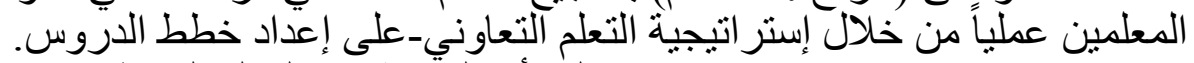

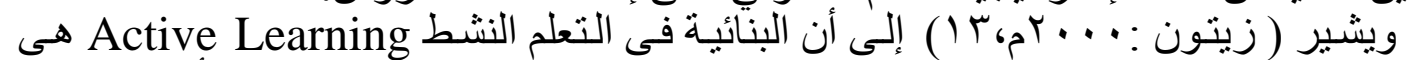

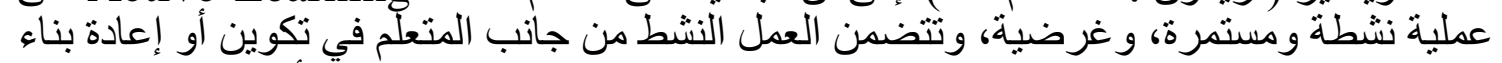

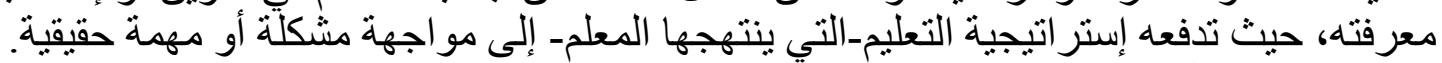

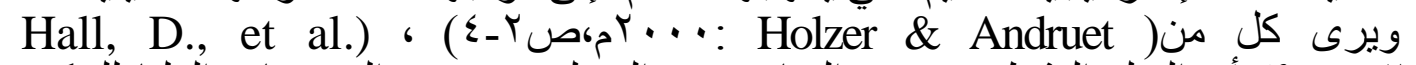

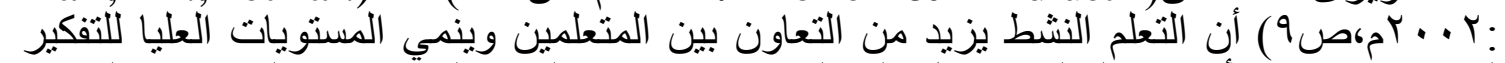

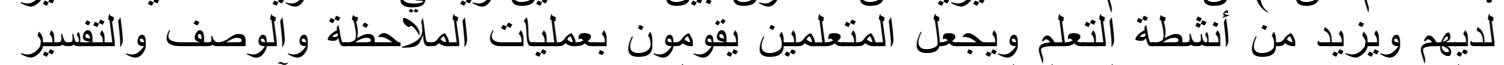

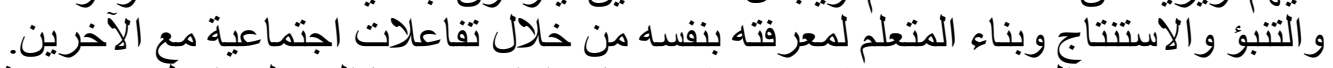

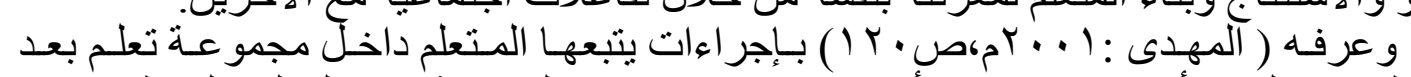

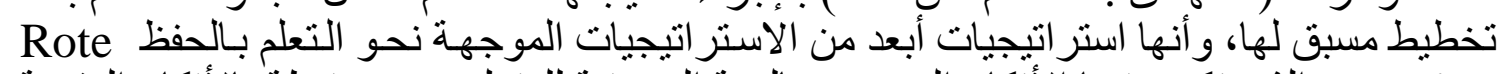
Learning

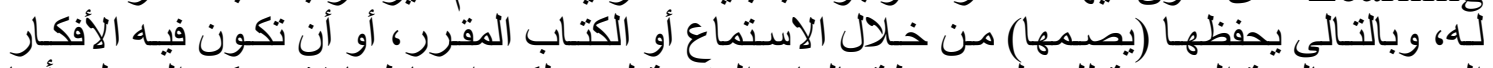

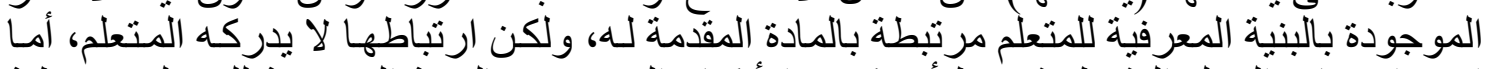

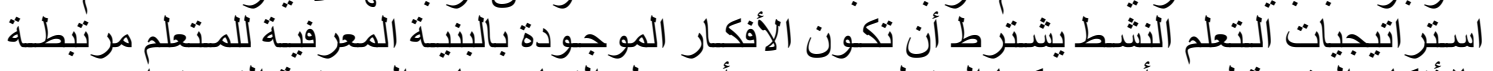

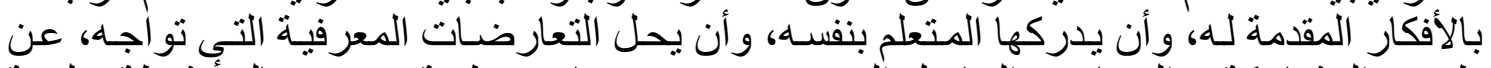

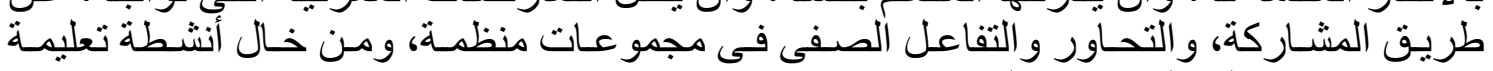

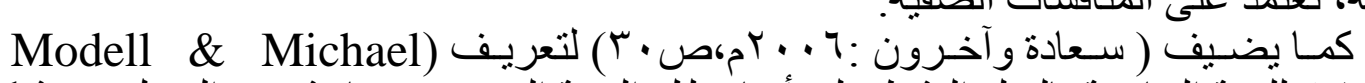

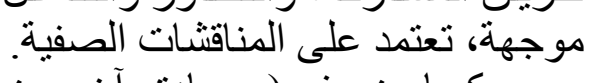

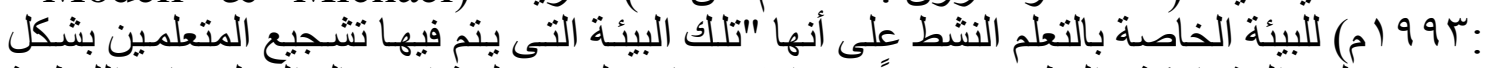

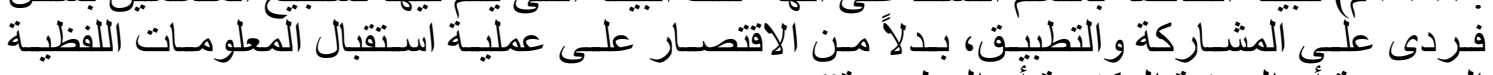

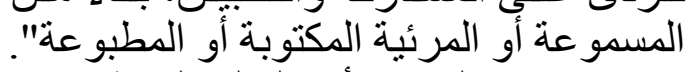

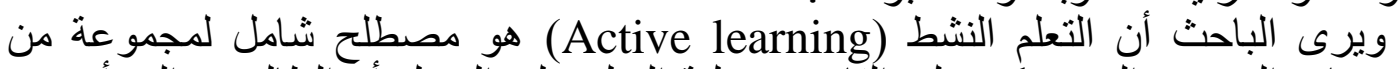

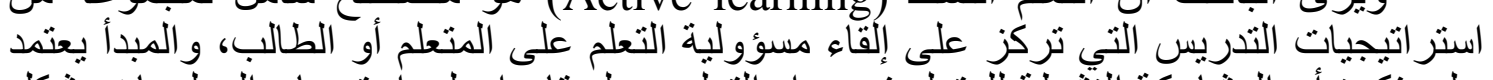

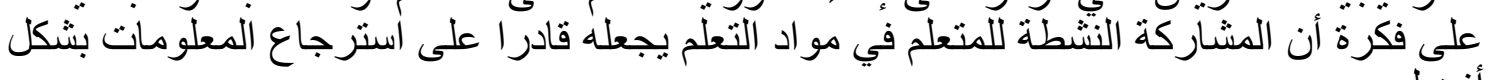

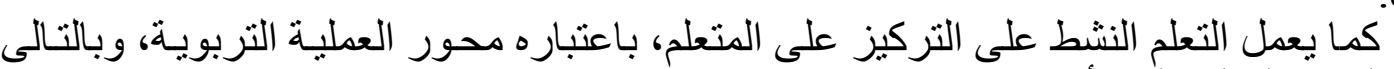

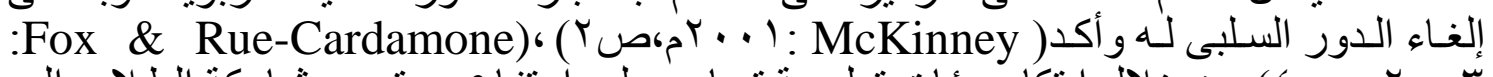

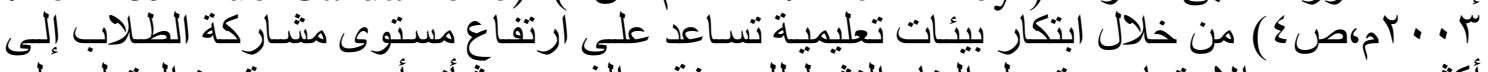

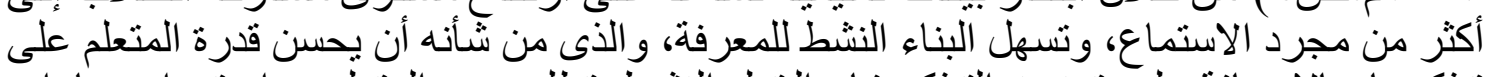

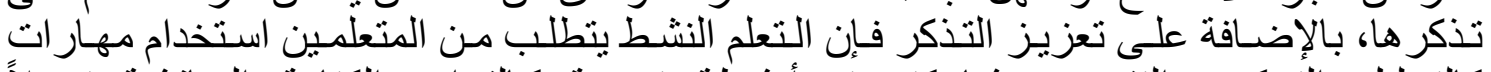

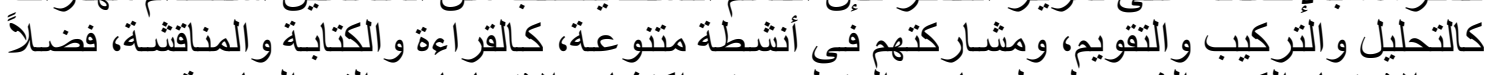

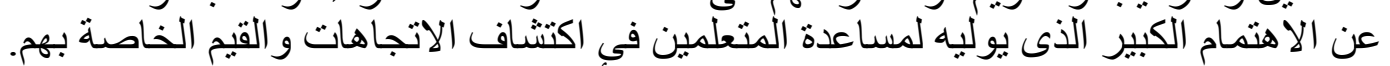

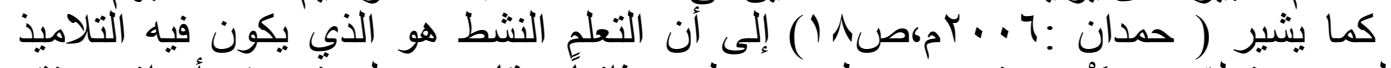

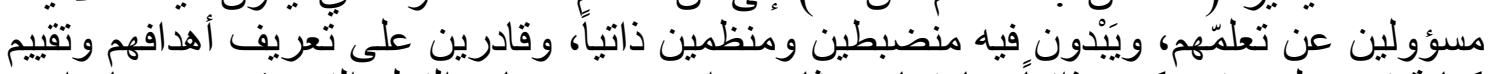

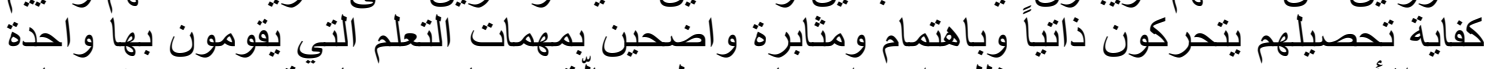

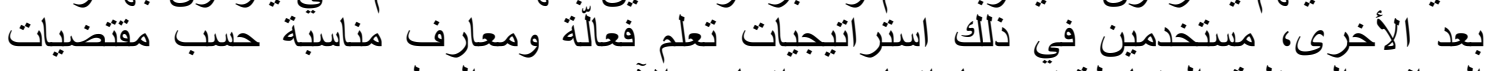
المو اقف المختلفة، المتفاعلة في مهار اتها وخبر اتها مع الآخرين من المعلمين. 


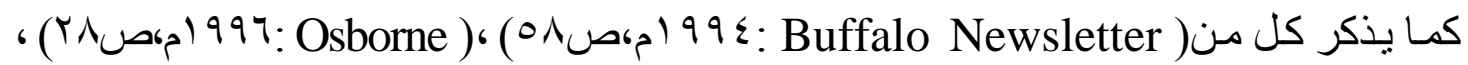

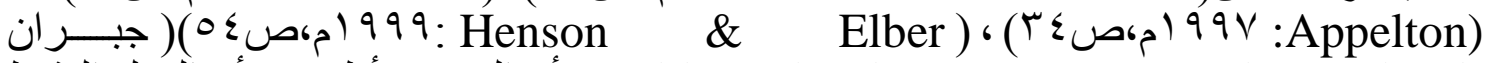

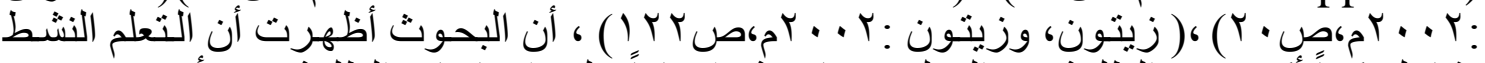

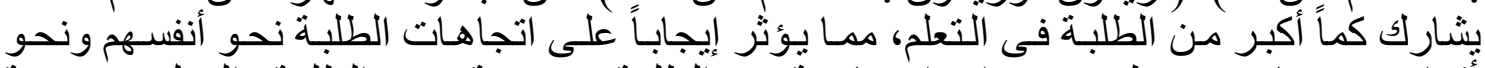

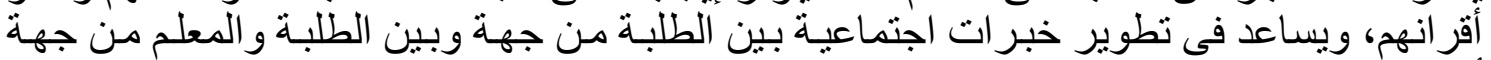

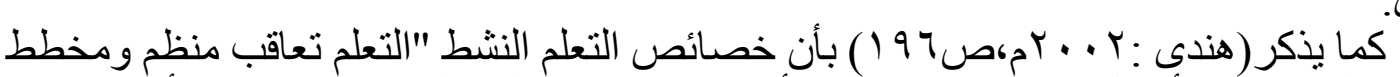

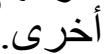

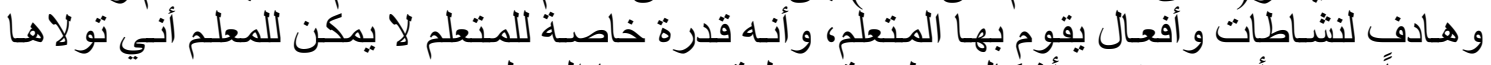

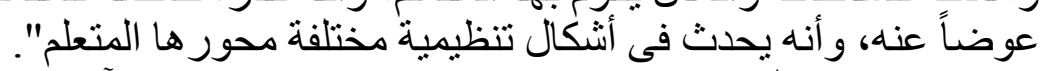

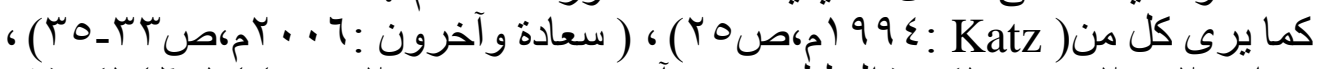

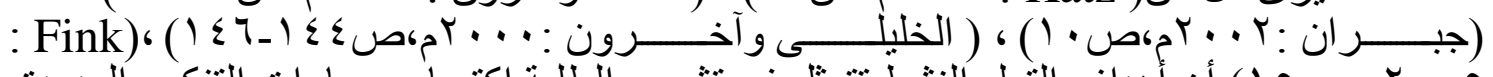

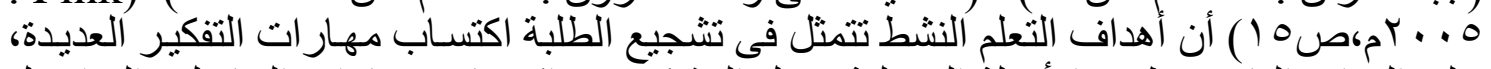

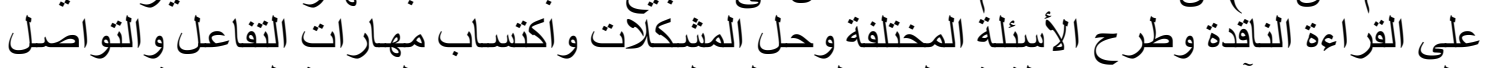

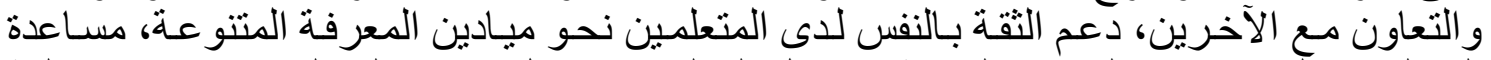

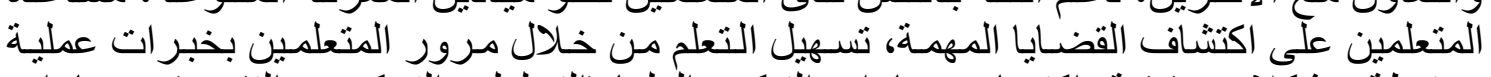

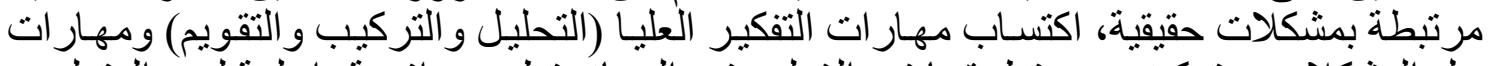
حل المشكلات، وتمكينهم من تطبيقها في التعلم وفى الحياة، تطوير دافعية داخلية لدئ لدى المتعلمين

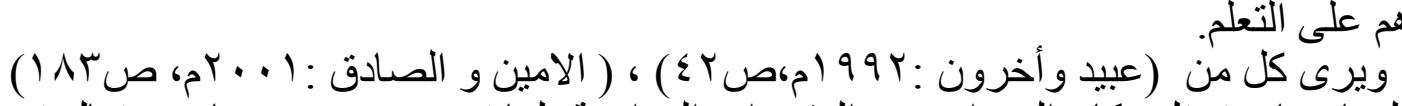

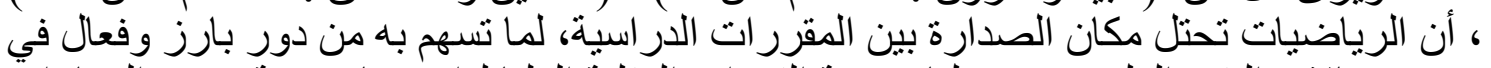

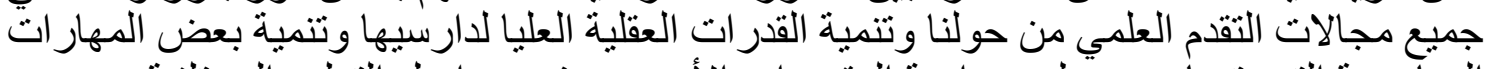

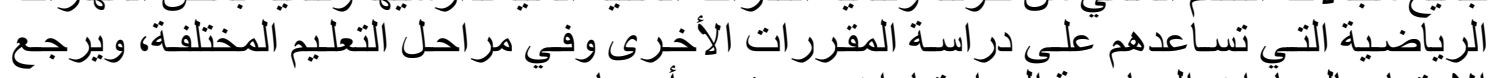

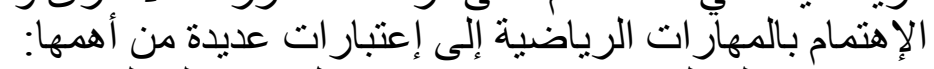

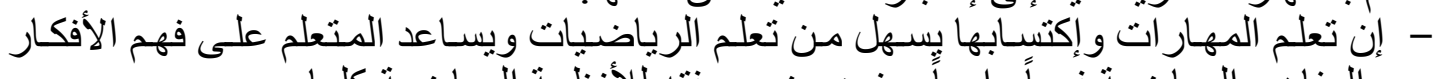

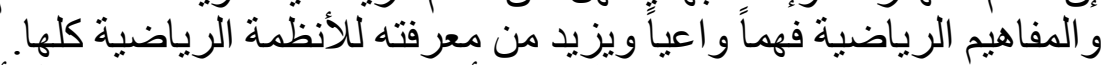

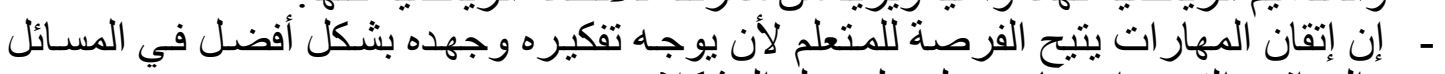

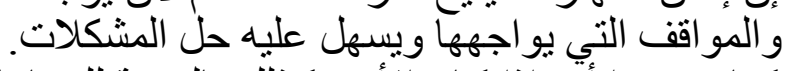

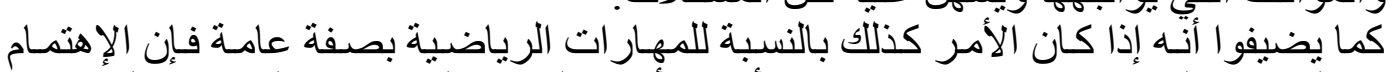

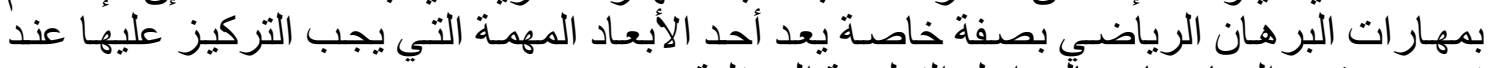
تدريس مقرر الرياضيات بألمر احل التعليمية المختلفة المهان.

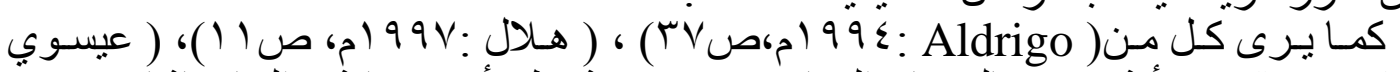

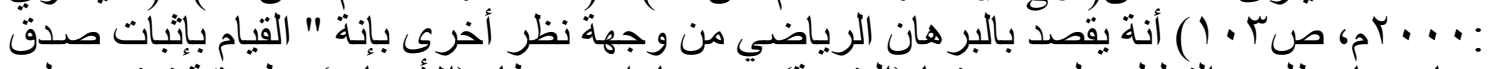

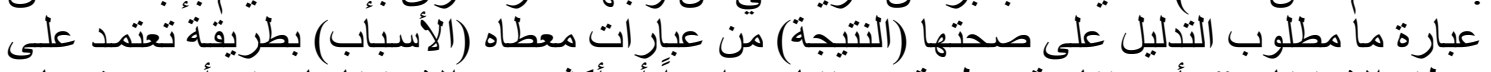

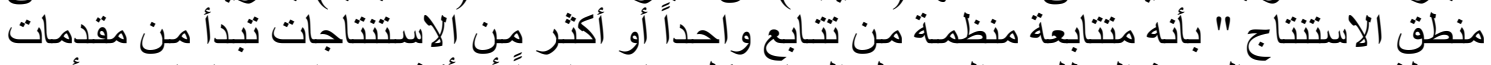

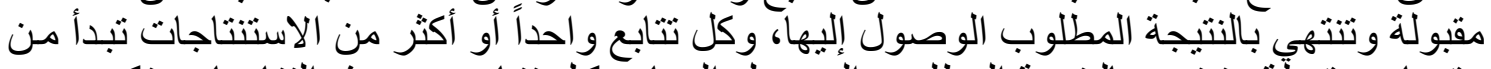

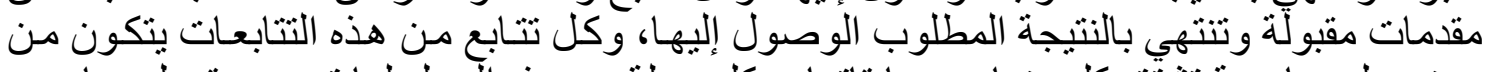

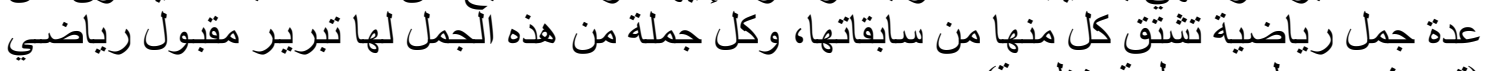
(تعريف، معطي، مسلمة، نظرية).

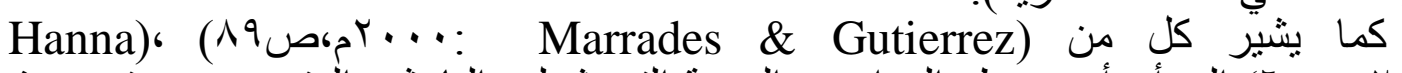

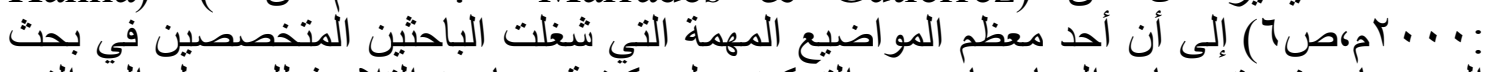

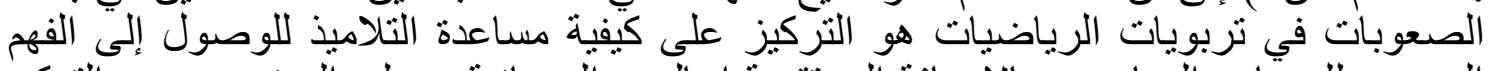

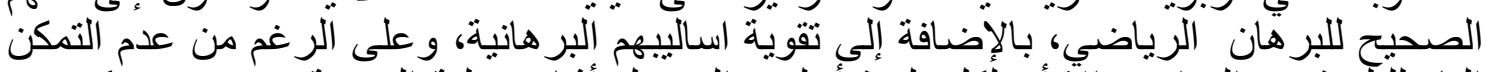

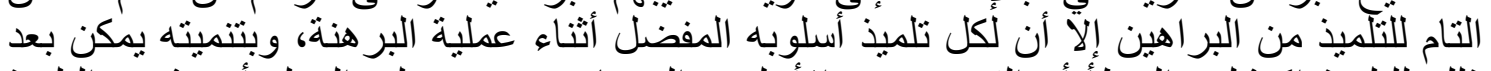
ذلك للتلميذ اكتثلف الخطأ أو القصور في الأسلوب المختار، ويجب على المعلم أن يثجع التلميذ 


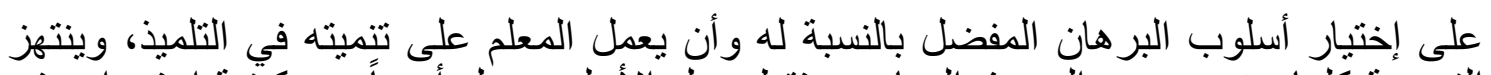

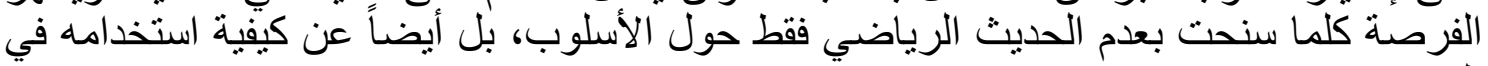

The Research Problem : مشكلة البحث

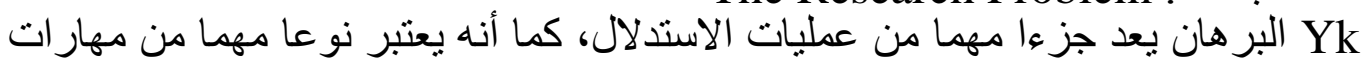

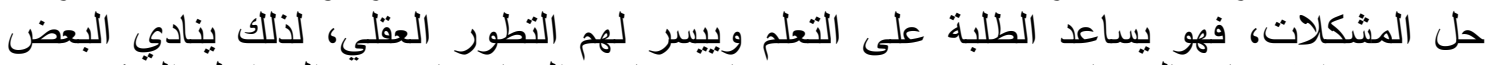

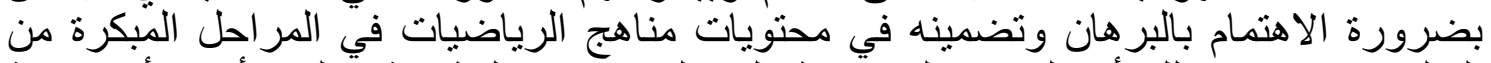

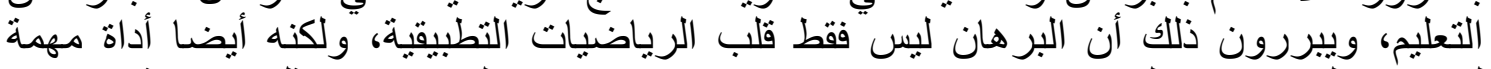

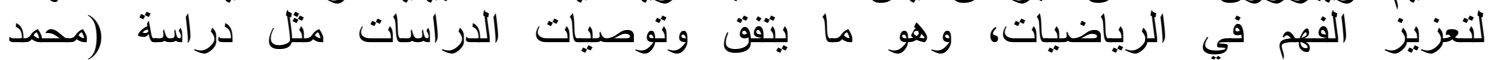

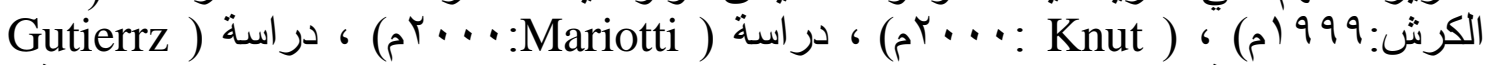

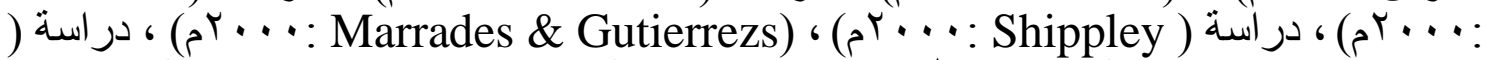

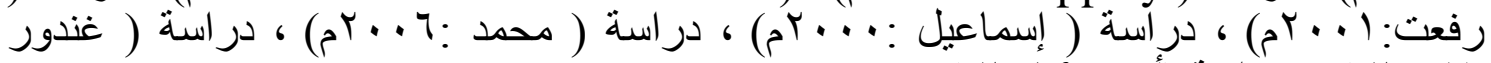

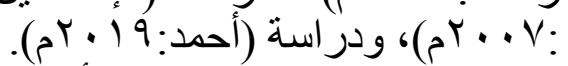

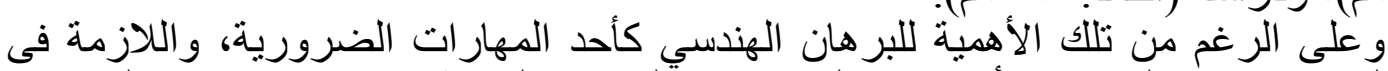

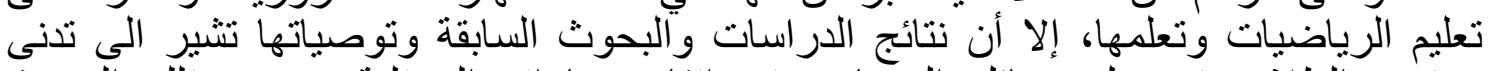

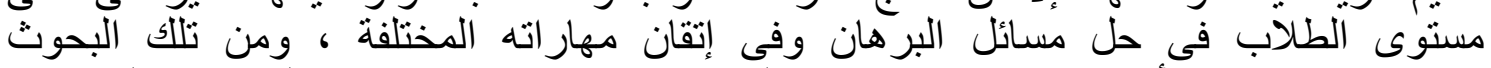

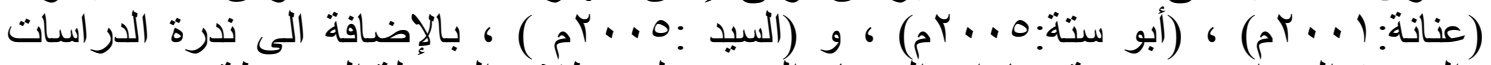

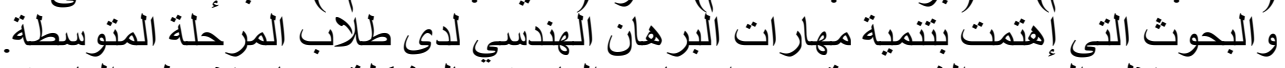

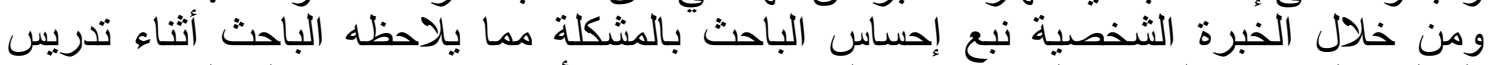

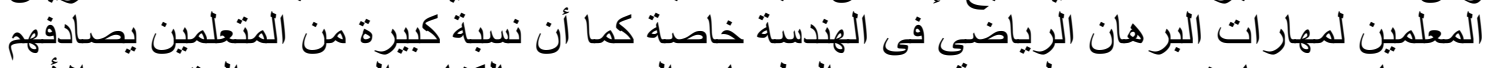

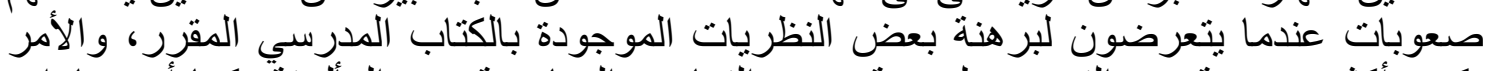

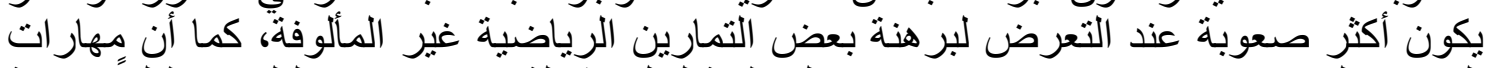

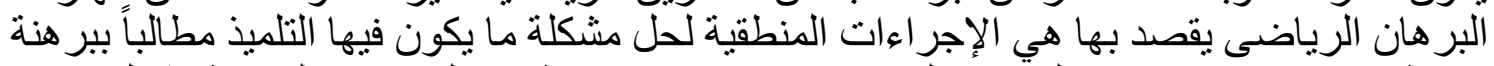

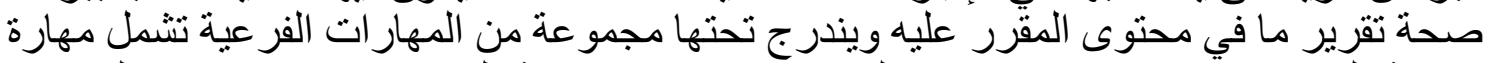

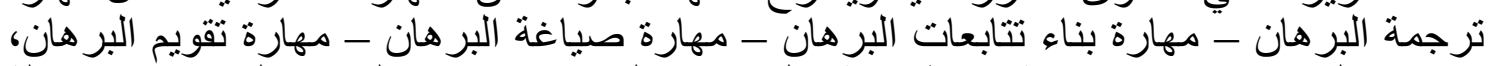

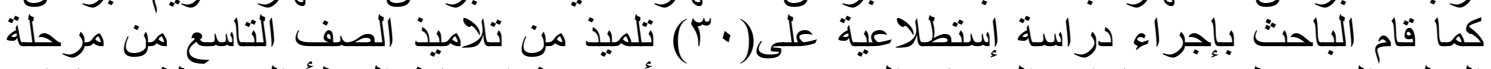

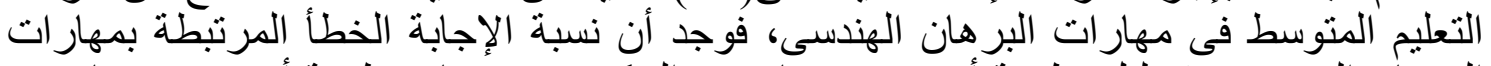

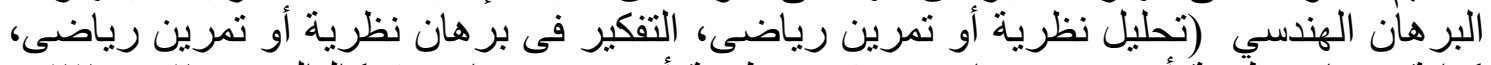

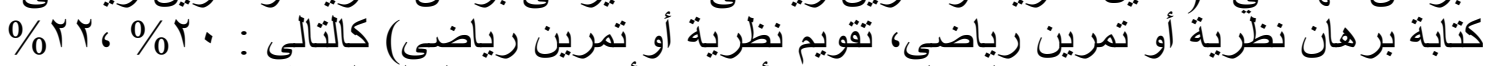

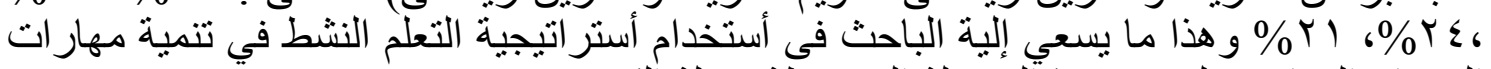

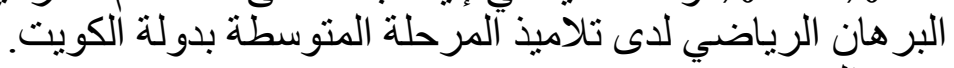

هدف البحث : The Research Purpose يهذف البحث : البحث الحالي إلى التعرف على استر اتيجية قائمة على التعلم النشط لتنمية

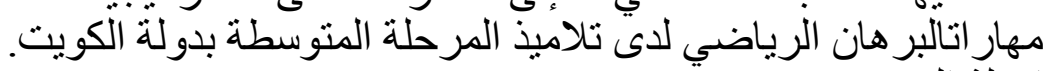

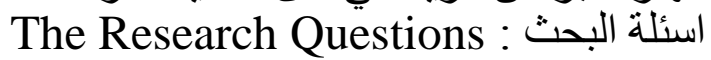
مأ فعالية استر اتيجية قائمة على التعلم النشط لتنمية مهار اتالبرهان الرياضي لدى تلاميذ

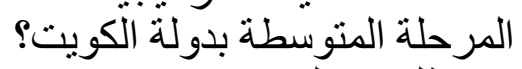

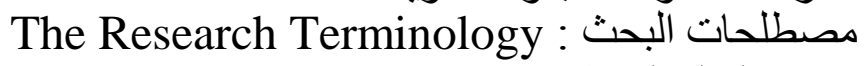

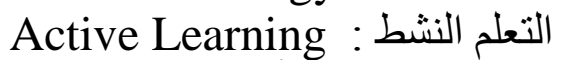

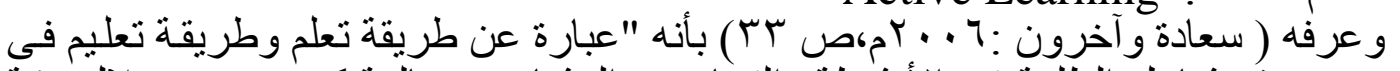

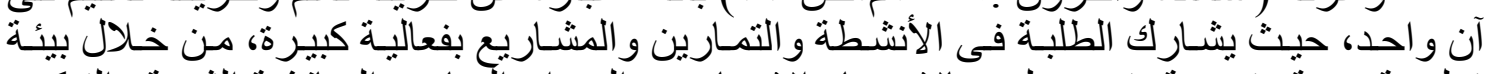

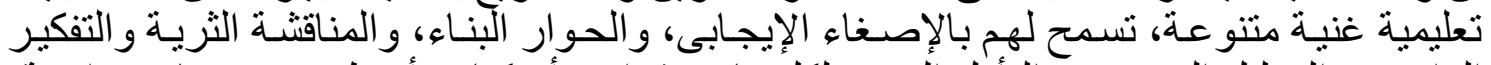

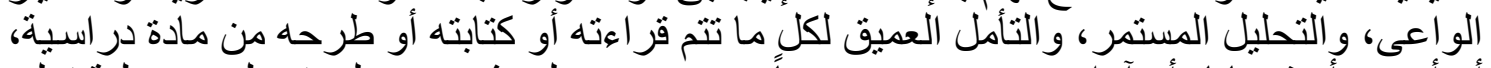

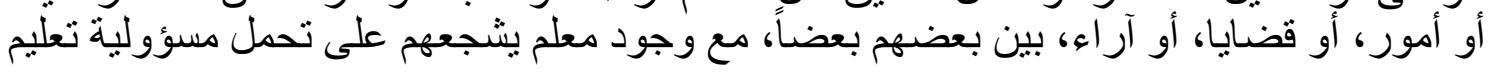




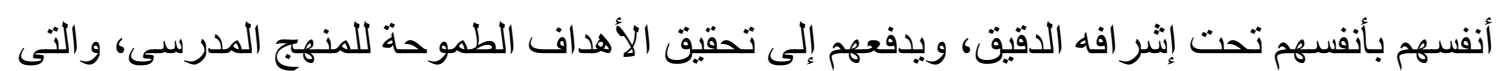

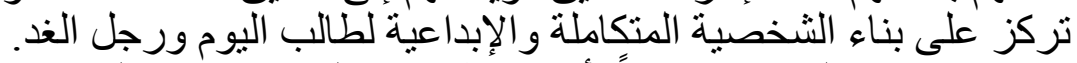

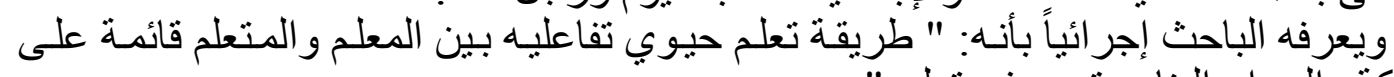

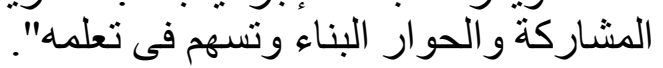

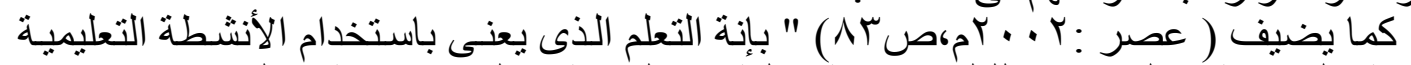

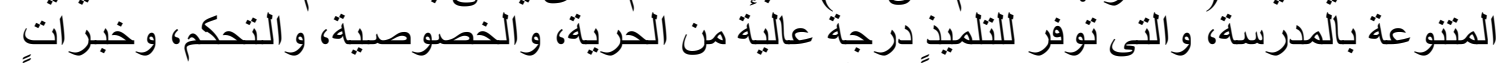

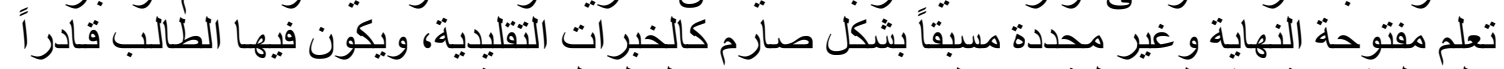

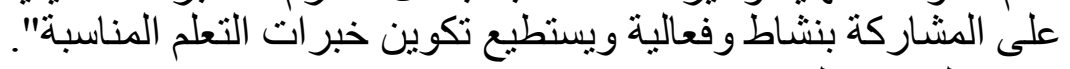

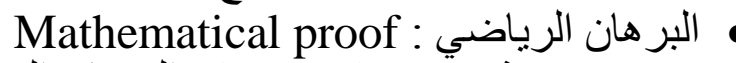

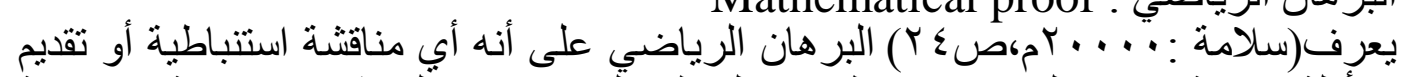

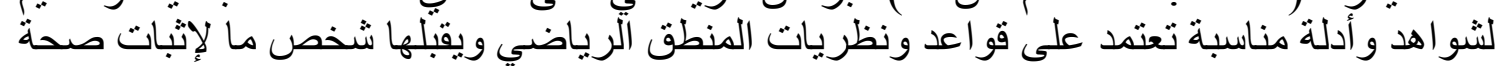
قضية رياضية معينة.

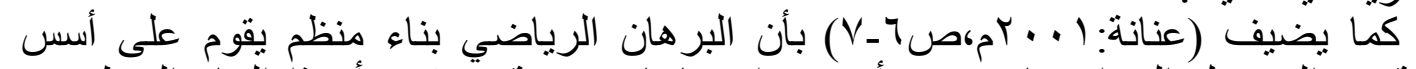

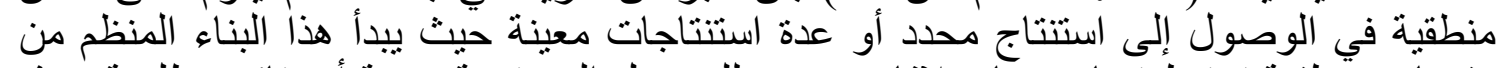

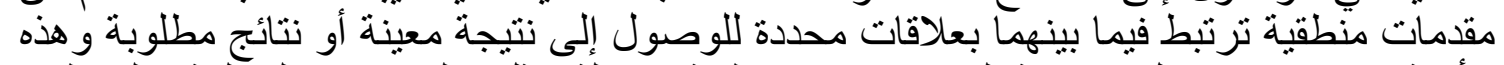

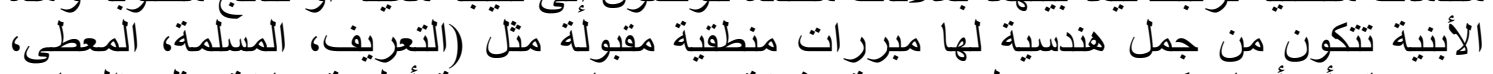

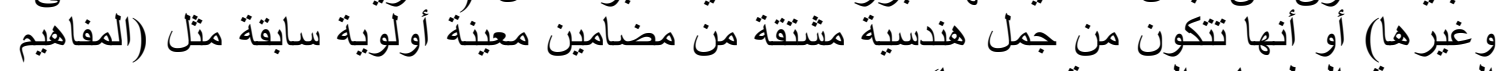

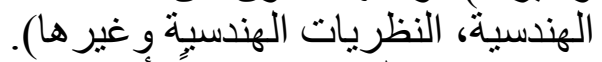

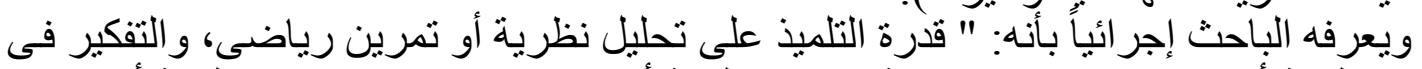

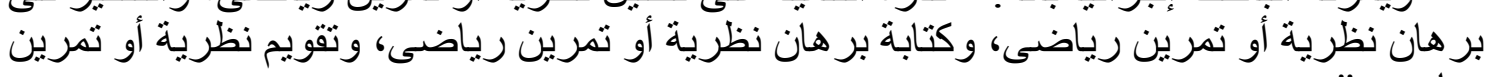

The Research Curriculum : رنهج البحئ.

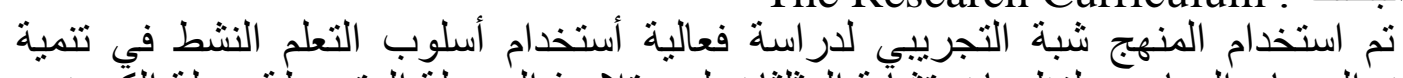

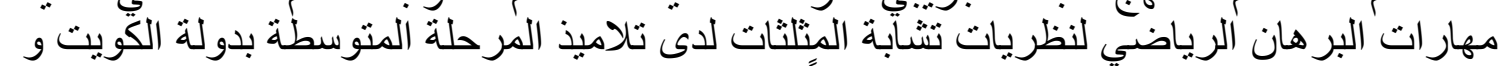

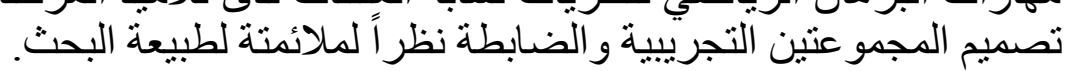

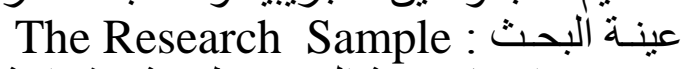
تم اختيار عينة البحث بطريقة عشو ائية من تلاميذ المرحلة المتوسطة بدولة الكويتً، بمنطقة

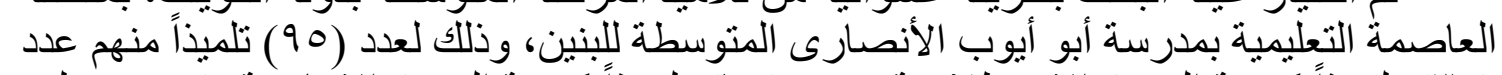

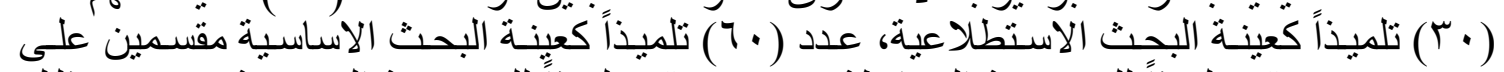

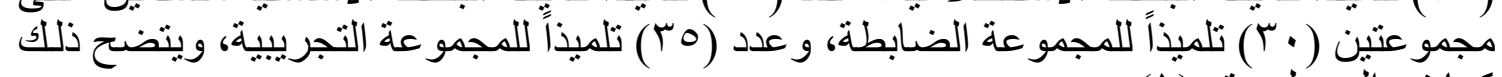

جدول (1) (1) (ل)

كما فى الجدول رقم (1) (1).

توصيف عينة البحث الكلية

\begin{tabular}{|c|c|c|c|}
\hline النسبة المئوية & العينة & البيان & مسلسل \\
\hline$\%\urcorner \wedge, \leqslant Y$ & 70 طالب & العينة الاساسية & 1 \\
\hline$\%$ \% & • ب طالب & العينة الاستطلاعية & $r$ \\
\hline$\%$ & 90 طالب & الاجمالي & $\mu$ \\
\hline
\end{tabular}

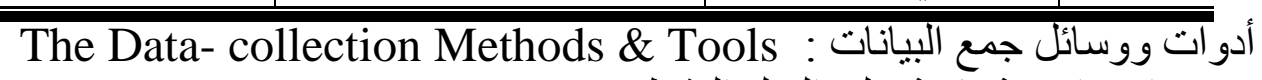

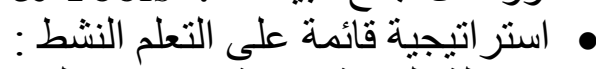

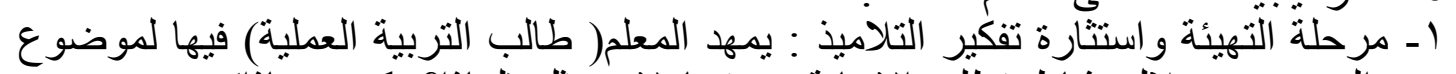

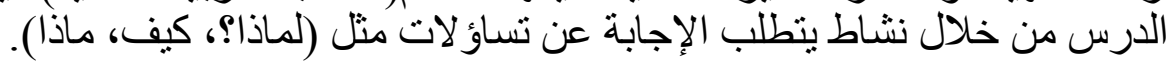




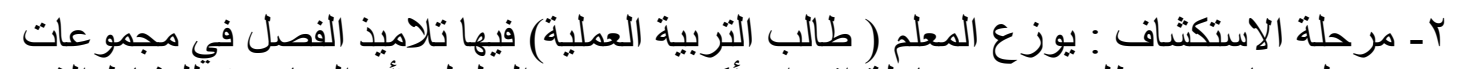

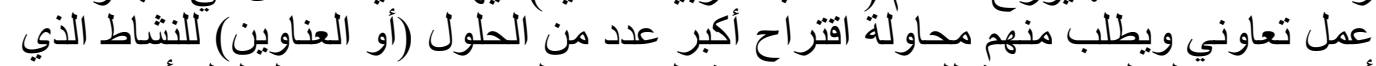

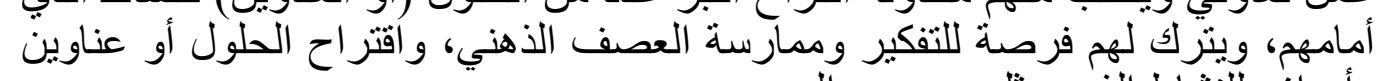

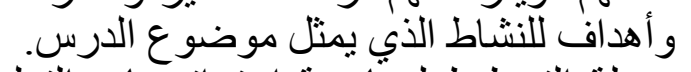

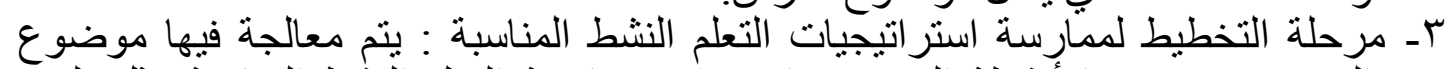

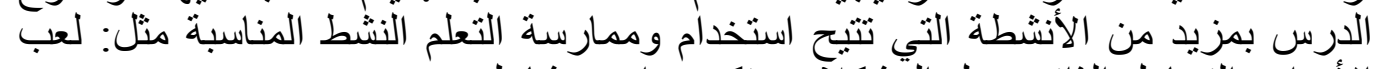

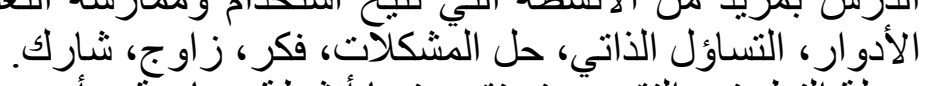

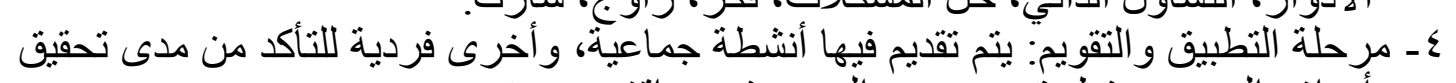

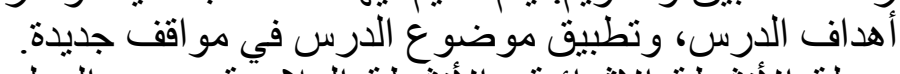

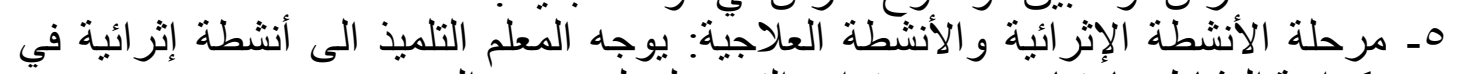

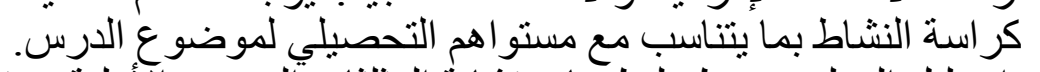

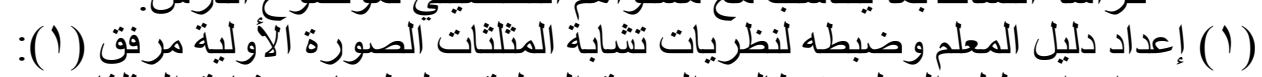

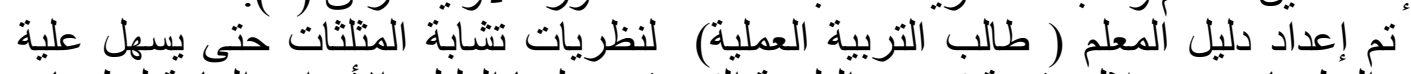

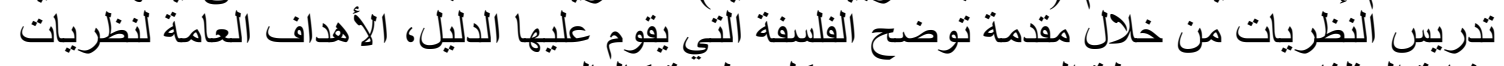

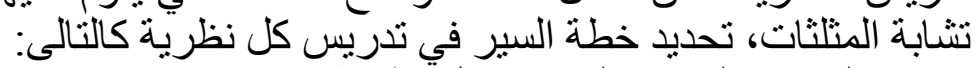

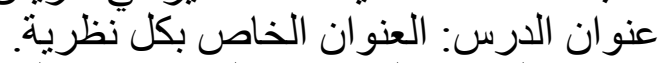

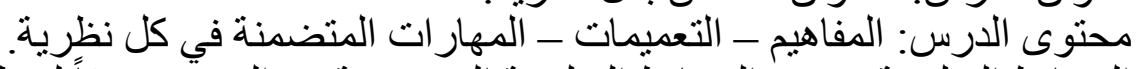

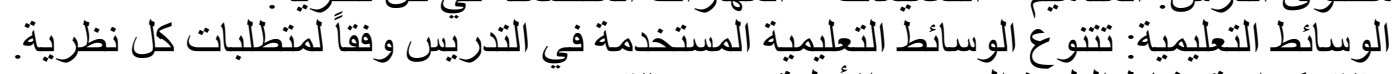

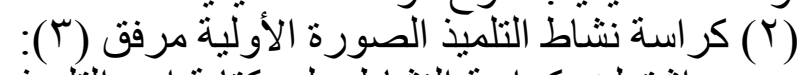

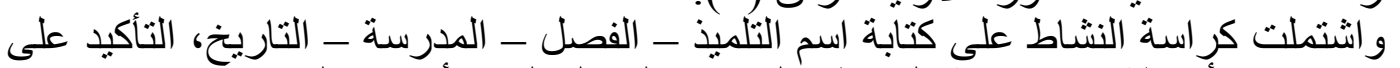

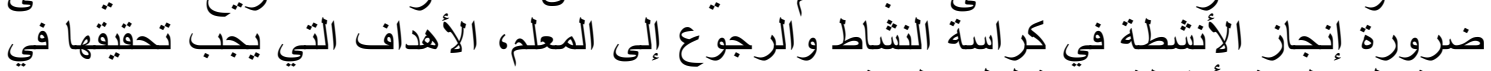
نهاية كل نظرية، أنشطة فردية النشة في لكل نظرية.

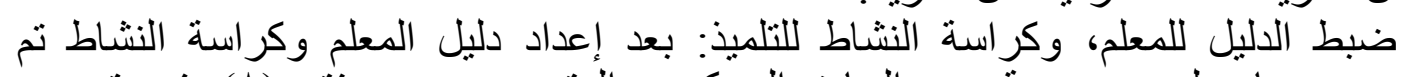

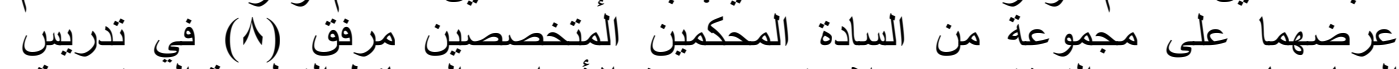

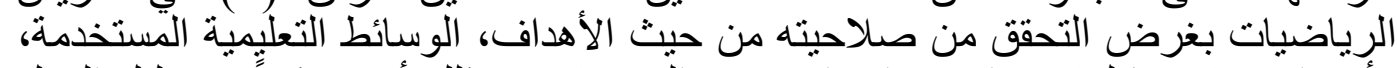

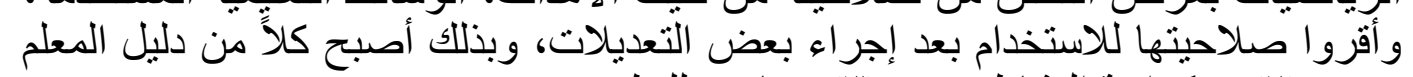

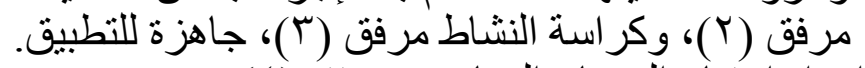

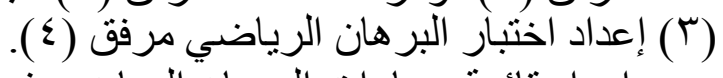

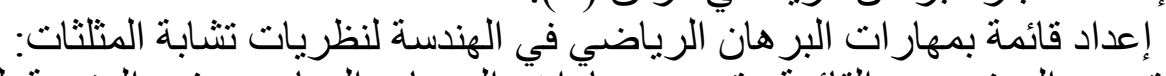

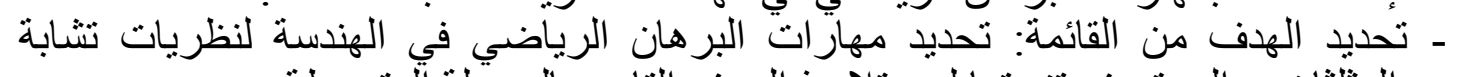

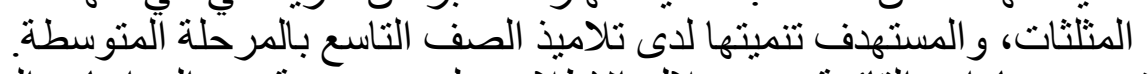

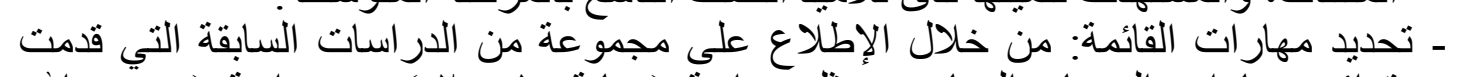

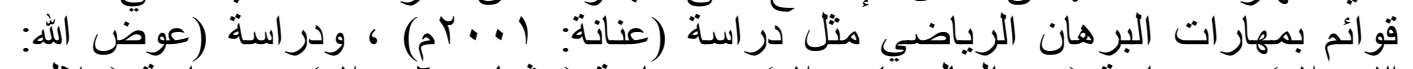

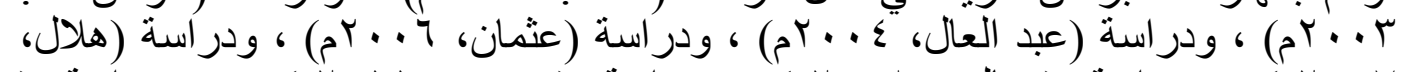

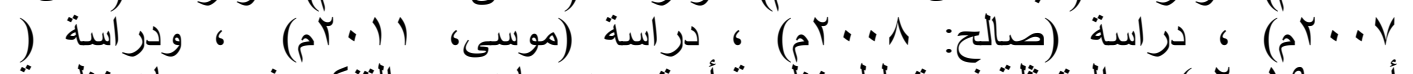

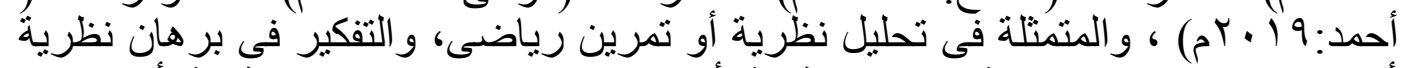

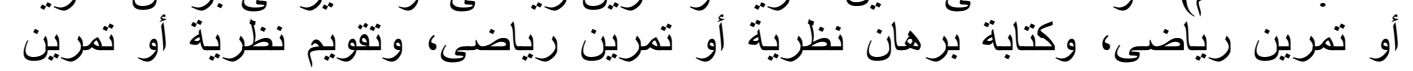
رياضى. • إعداد اختبار البرهان الرياضي في الهندسة لنظريات تنثابة المثلثات:

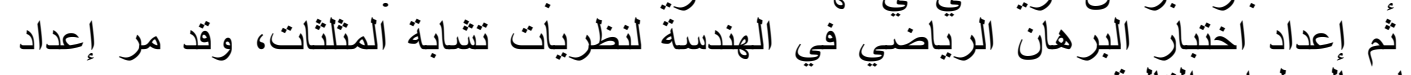
الاختبار بالخطو ات ألتاد التالية:

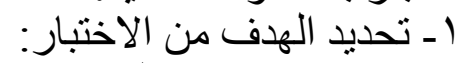
يهدف الاختبارِ إلى قياس الإبار: مهار ات البر هان الرياضي في الهندسة، و التي تشمل:

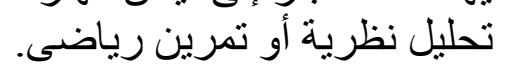




$$
\begin{aligned}
& \text { ا التفكير فى بر هانة نظرية أو تمرين رياضى. }
\end{aligned}
$$

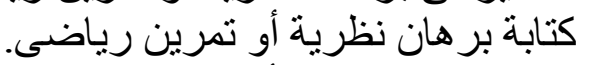

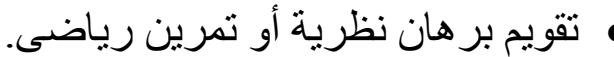

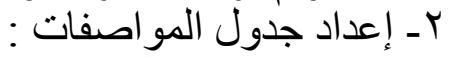

$$
\begin{aligned}
& \text { تم إعداد جدول مو اصفات للاختبار : }
\end{aligned}
$$

تحديد الأهمية بالوزن النسبي لنظريات تشابة المثلثات بالنسبة لموضو عات التات الوحدة:

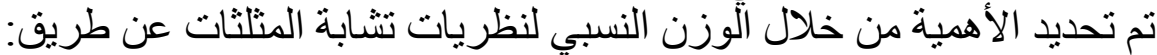
- تقدير عدد الصفحات التي تشغلها نظريات تشابة المنلثات بالنسبة لعدد صفحات المئن الموضوع

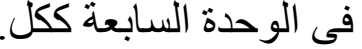

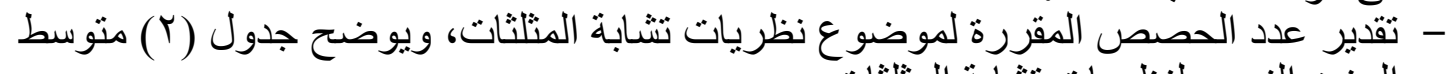

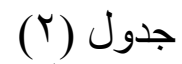
الوزن النسبي لنظريات تشابة المثلثات. متوسط الوزن النسبي لموضو عات نظريات تشابة المثلثات

\begin{tabular}{|c|c|c|c|c|c|}
\hline \multirow{2}{*}{ متوسط الوزن } & \multicolumn{2}{|c|}{ الحصص } & \multicolumn{2}{|c|}{ الصفحات } & \multirow{2}{*}{ موضوع الدرس } \\
\hline & النسبة & العدد & النسبة & العدد & \\
\hline$\% r \leqslant, 09$ & \% & $\varepsilon$ & $\% \backslash, \wedge Y$ & 0 & 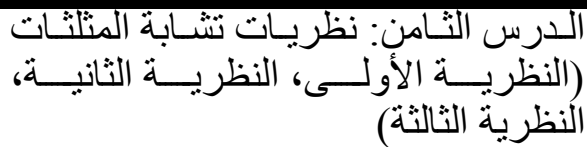 \\
\hline
\end{tabular}

- تحديد عدد المفردات التي بتضمنها الاختبار و الخاصة بكل موضوع من موضو عات الوحدة: وذللك عن طريق المعادلةً التالية :

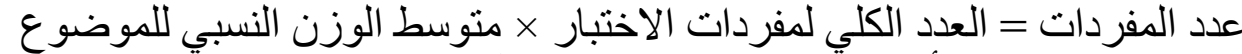

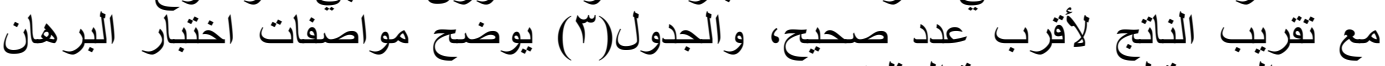
الرياضي في الهندسة لوحدة هندسة المثلث.

$$
\text { جدول (ب) }
$$

\begin{tabular}{|c|c|c|c|c|c|}
\hline \multirow{2}{*}{ | } & التقويم & الكتابة & التفكير & التحليل & \multirow{2}{*}{ الموضولوع البر هان الرياضي } \\
\hline & آرقام المفردات & آرقام المفردات & آرقام المفردات & آرقام المفردات & \\
\hline - & السؤال الر ابع & السؤ ال الخامس الثالث & 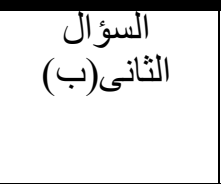 & 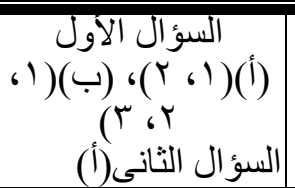 & المثلثات الثتشابهابة. التشابه، \\
\hline$r$ & $\varepsilon$ & $\varepsilon$ & 9 & 14 & المجموع \\
\hline
\end{tabular}

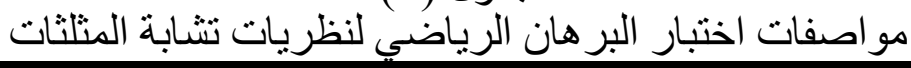

• تحديد مفردات الاختبار : من خلال الإطلاع على مجمو عة من الدر اسات التي تناولت إعداد

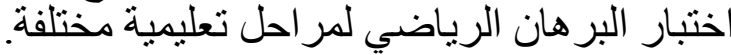

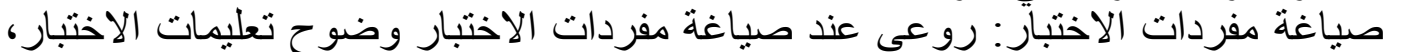

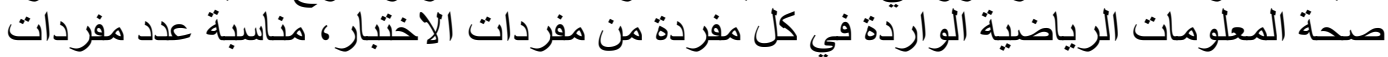

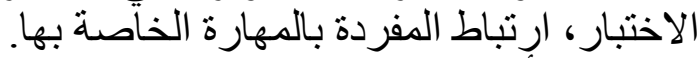

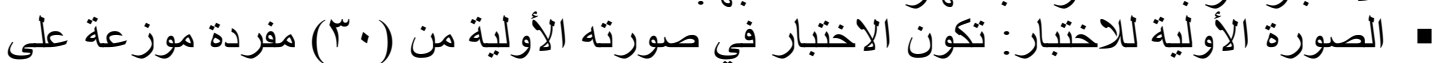

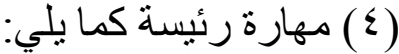

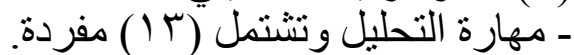

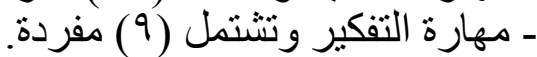

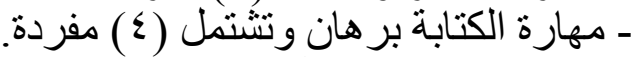

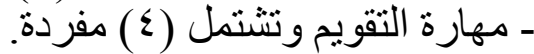


وتم عرض الاختبار في صورته الأولية على مجموعة من السادة المحكمين في مجال الرال

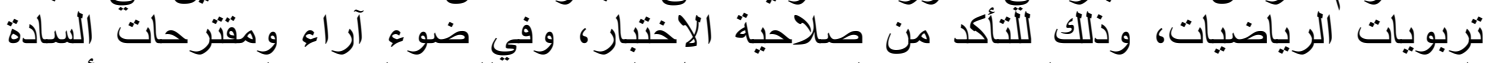

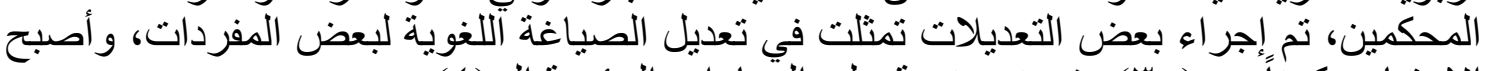

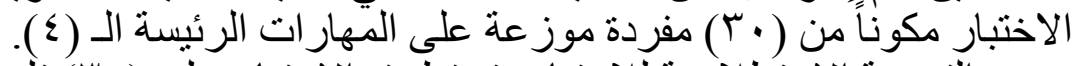

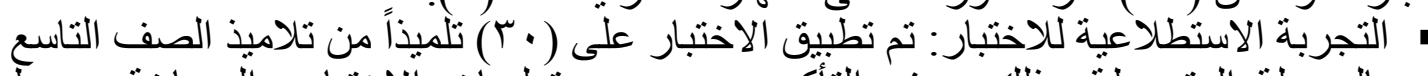

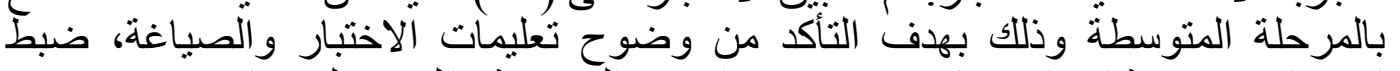

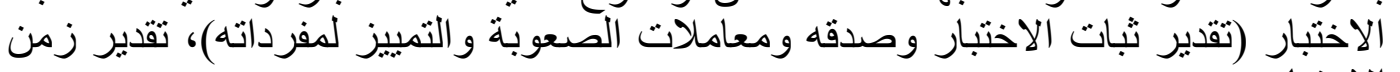
الاختبار.

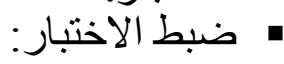

1 ـ ثبات الاختبار: تم حساب ثبات الاختبار من خلال رصد درجات دات التبار التجربة الاسنطلاعية

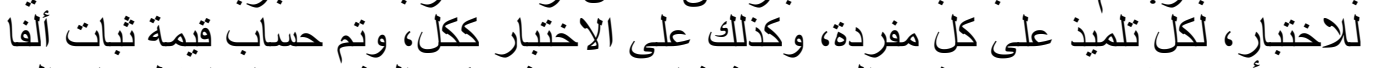

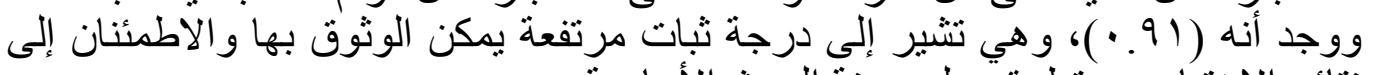

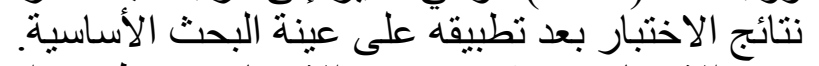

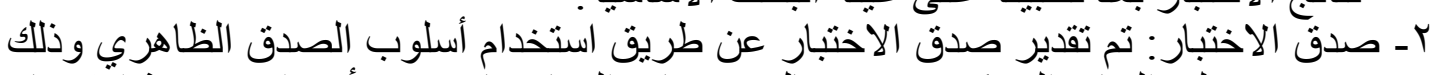

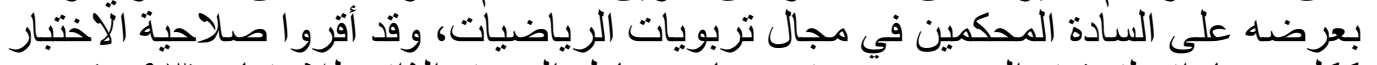

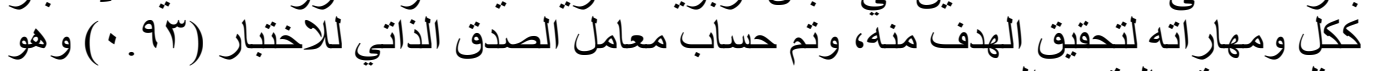
يمثل درجة ومهار عالية من التهفئ الصدق.

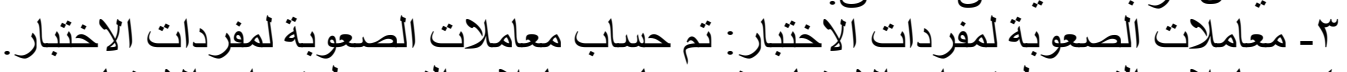

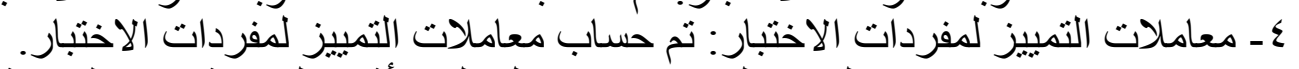

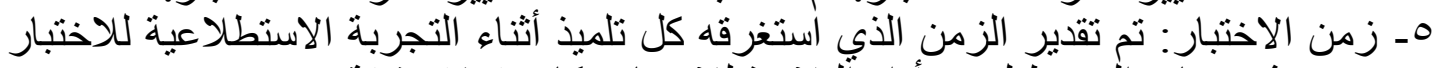

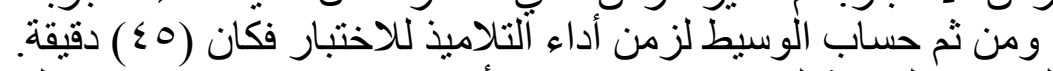

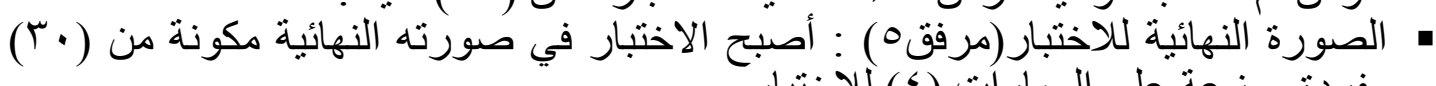

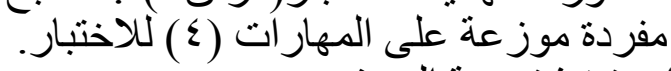
إجر اءات تتفيذ تجربة البحثى: على الجئ:

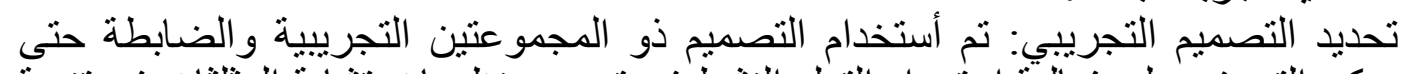

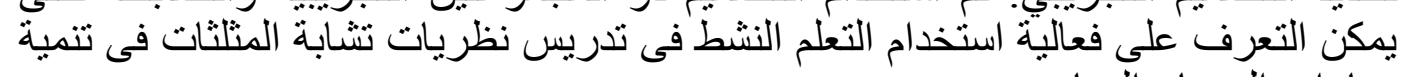

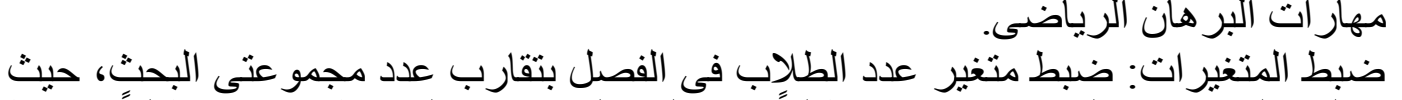

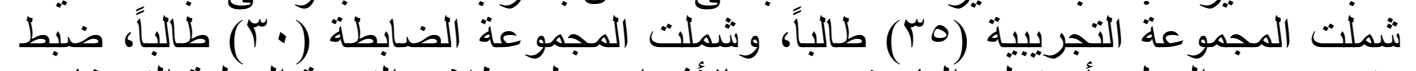

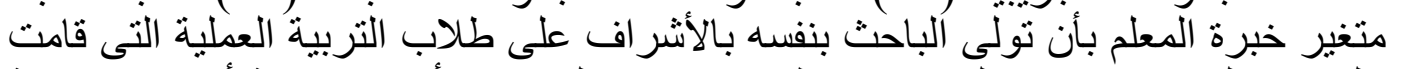

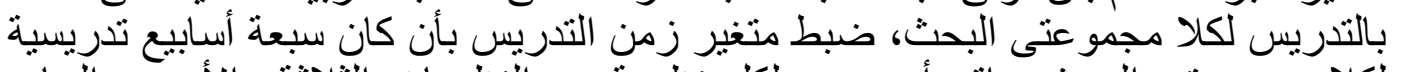

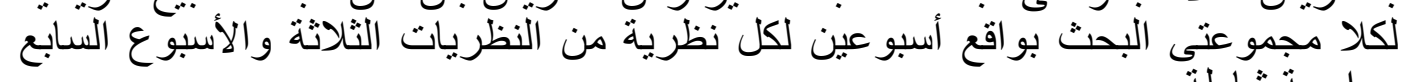
مر اجعة شاملة. التطبيق القبلى للاختبار ات: تم تطبيق اختبار البرهان الرياضى لنظريات تشابة المثلثنات قبلياً

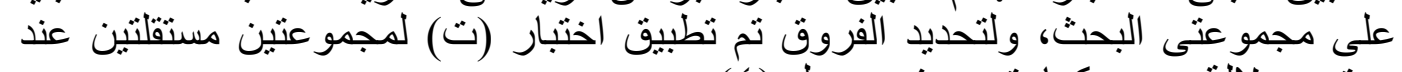

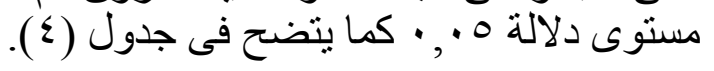




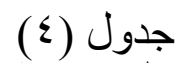

دلالة الفروق بين المجموعة التجريبية والمجموعة الضباطة فى اختبار البرهان الرياضى

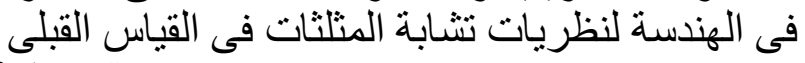

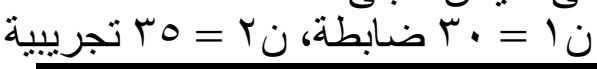

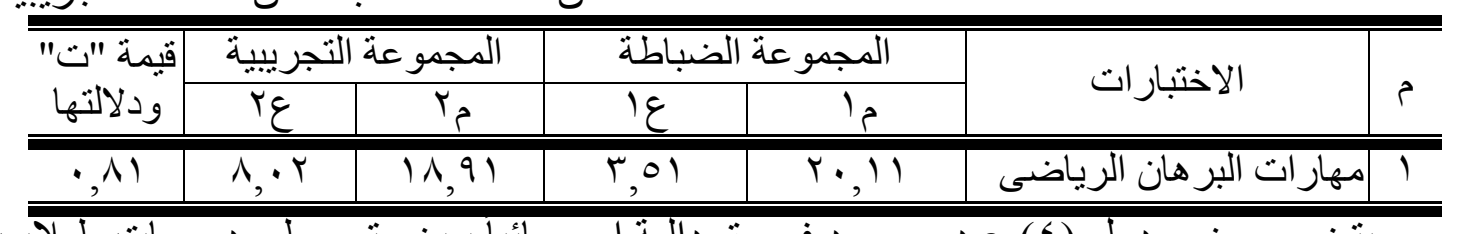

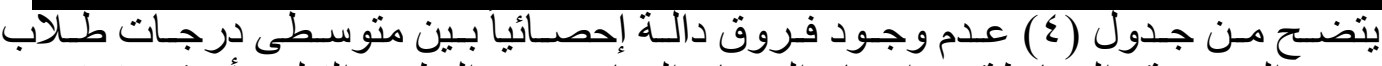

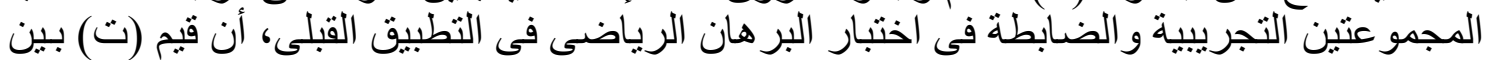

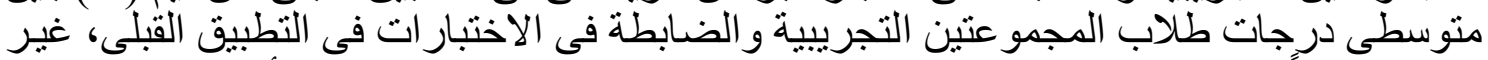

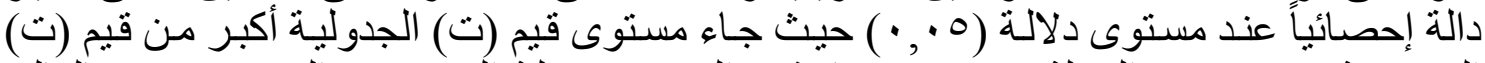

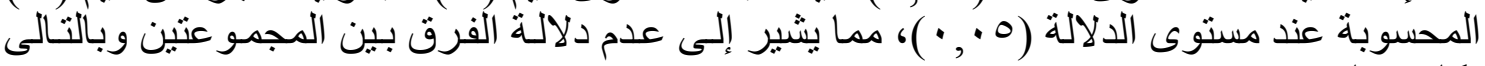

تدريس وحدة هندسة المثلث: بعد تطبيق الاختبار ات قبلياً على مجمو عتى البحث، ثم التدريس تكافؤ هما.

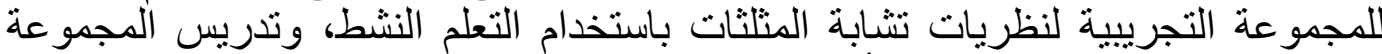

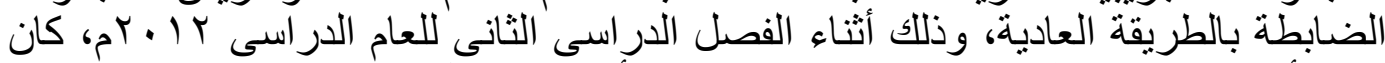

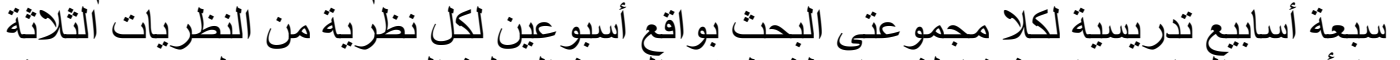

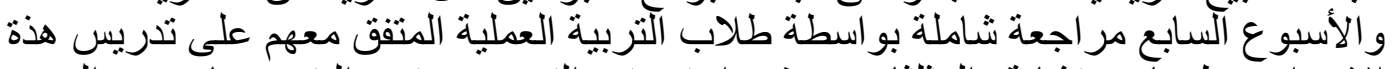

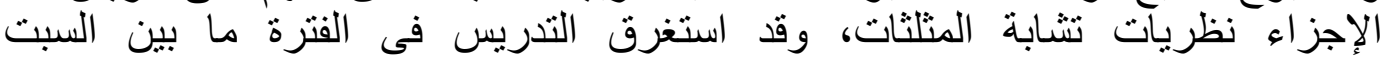

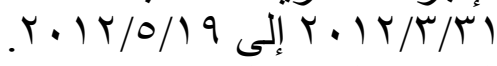

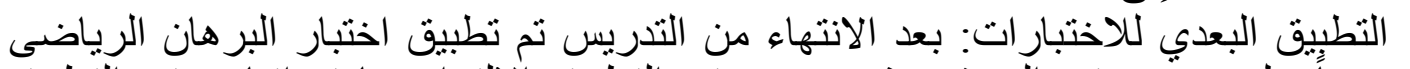

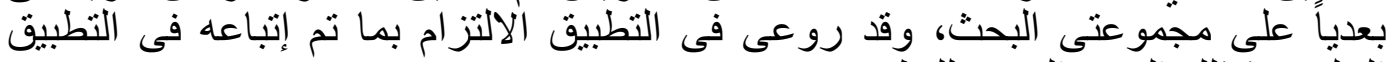

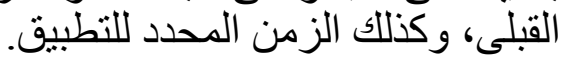

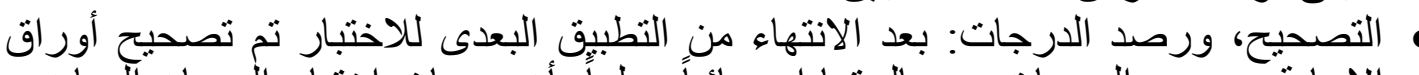

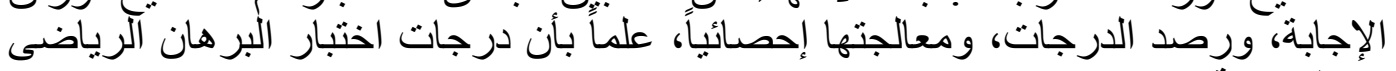

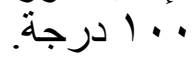
خطة المعالجة الإحصائية:

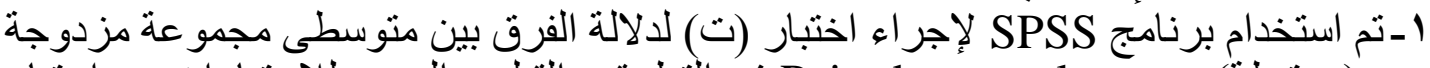

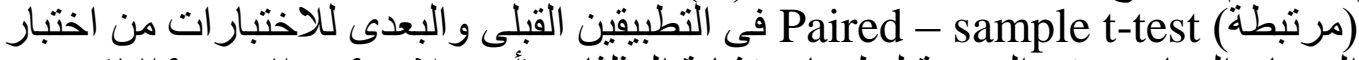

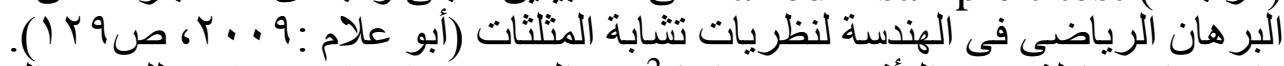

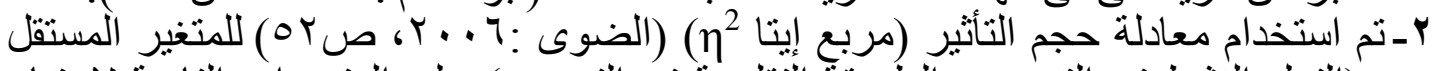

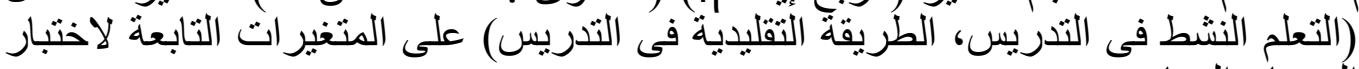

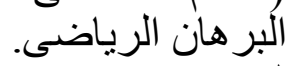

عرض النتائج ومناقتشتها: Presenting The Results And Discussion جدول (0)

عرض النتائج: Pرضج ومن Presenting The Results

دلالة الفرق بين القياس القبلى والبعدى للمجمو عة التجريبية فى مهار ات البرهان الرياضى

ن = هـ تجريبية ل اللاختبار ككل

\begin{tabular}{|c|c|c|c|c|c|c|}
\hline \multirow{2}{*}{ قيمة "تلاتلها } & \multicolumn{2}{|c|}{ القياس البعدى } & \multicolumn{2}{|c|}{ القياس القبلى } & \multirow{2}{*}{ الاختبار ات } & \multirow{2}{*}{ r } \\
\hline & $r_{\varepsilon}$ & $r^{5}$ & $1 \varepsilon$ & م & & \\
\hline$* 11,11$ & r, & $r \cdot, 0$. & $r, 90$ & $1 \cdot, 01$ & التحليل & 1 \\
\hline
\end{tabular}




\begin{tabular}{|c|c|c|c|c|c|c|}
\hline *17, ro & T,YY & $17, \wedge 1$ & 1,97 & $0, \wedge \Gamma$ & التفكير & r \\
\hline$* 1 \leqslant, 1\}$ & $9, \times 0$ & $r \leqslant, \wedge$ & $1, Y 7$ & $1, \leqslant 0$ & 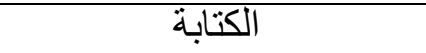 & $r$ \\
\hline$* 17,177$ & $\varepsilon, 10$ & $1 T, 7 r$ & 1,4 & 1,0 & تقويم & $\varepsilon$ \\
\hline$* 1 \wedge, r_{0}$ & $r \cdot, \leqslant \Lambda$ & $\mathrm{VO}, \mathrm{VM}$ & $\Lambda, \cdot Y$ & 11,91 & اختبار البرهان الرياضى ككل & 0 \\
\hline
\end{tabular}

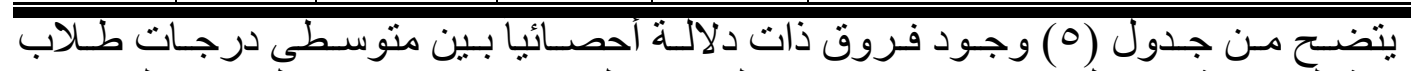

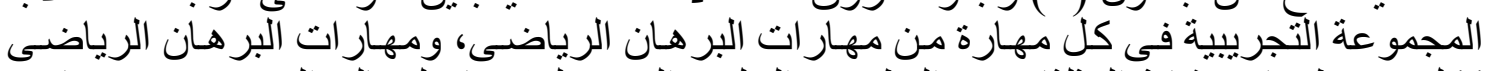

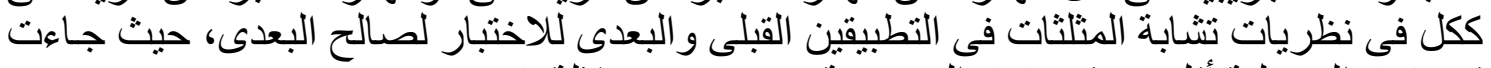

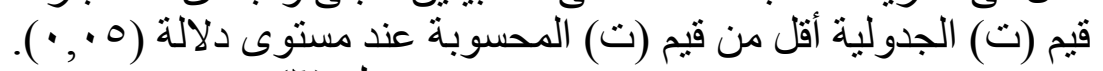
جدول (T) جدون

دلالة الفرق بين المجمو عة التجريبية و المجموعة الضابطة فى مهار ات ات البرهان الرياضى للاختبار ككل فى القياس البعدى

نا

\begin{tabular}{|c|c|c|c|c|c|c|}
\hline \multirow{2}{*}{ وقيمة "قاتله" } & \multicolumn{2}{|c|}{ المجمو عة التجريبية } & \multicolumn{2}{|c|}{ المجمو عة الضابطة } & \multirow{2}{*}{ الاختبار ات } & \multirow[b]{2}{*}{ r } \\
\hline & $r_{\varepsilon}$ & مج & I & مج & & \\
\hline$* \Lambda, \mu \tau$ & 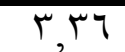 & $r \cdot, 0$. & $r, 90$ & $1 \leq, \mu$ & التحليل & 1 \\
\hline$* r, 90$ & r,YY & $17, \wedge 1$ & $r, \wedge$ & $1 \Gamma, \wedge T$ & التفكير & r \\
\hline$* \varepsilon, V V$ & $9, \times 0$ & $r \varepsilon, \wedge$ & $7, r_{0}$ & $1 \varepsilon, \wedge r$ & 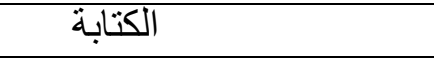 & $\mu$ \\
\hline$*\rceil, \wedge 7$ & $\varepsilon, 10$ & $1 T, 7 T$ & $r, 11$ & $V, V I$ & تقويم & $\varepsilon$ \\
\hline$* V, \cdot V$ & $r \cdot, \leqslant \Lambda$ & $\mathrm{VO}, \mathrm{VT}$ & $10, \leqslant 9$ & $0 \cdot, \mathrm{V} \cdot$ & اختبار البر هان الرياضى ككل & 0 \\
\hline
\end{tabular}

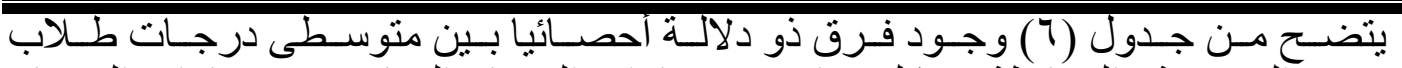

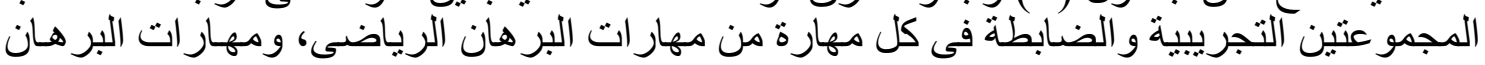

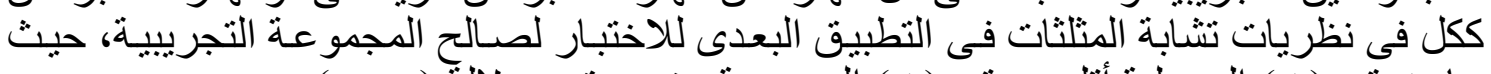

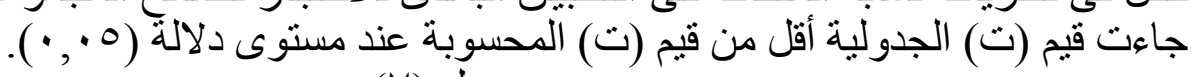
جدول (v) (ل)

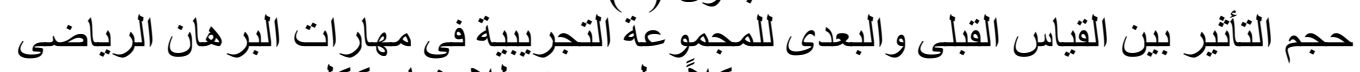

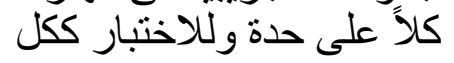

ن

\begin{tabular}{|c|c|c|c|c|c|}
\hline قوة حتنثير & حجم التأثنير & قودلالتها "تا" & الحرية & الاختبار ات & r \\
\hline كبيرة & $\cdot, \mathrm{\vee} \wedge$ & $* 11,1 \pi$ & T乏 & التحليل & 1 \\
\hline كبيرة & .9. & $* 17, \mu_{0}$ & T纟 & التفكير & $r$ \\
\hline كبيرة & $\cdot, \wedge \wedge$ & $* 1 \varepsilon, 1 r$ & $\Gamma \varepsilon$ & 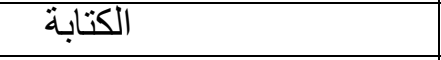 & $r$ \\
\hline كبيرة & $\cdot, \wedge 9$ & $* 17, \vee 7$ & $\Gamma \varepsilon$ & تقويم & $\varepsilon$ \\
\hline كبيرة & $\cdot, 9 \leq$ & $* 1 \wedge$, YO & Tร & اختبار البر هان الرياضى ككل & 0 \\
\hline
\end{tabular}

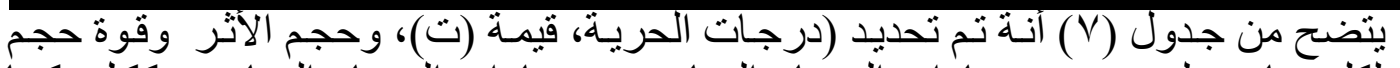

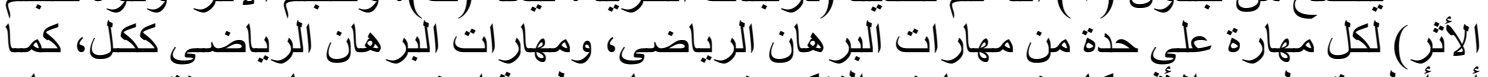

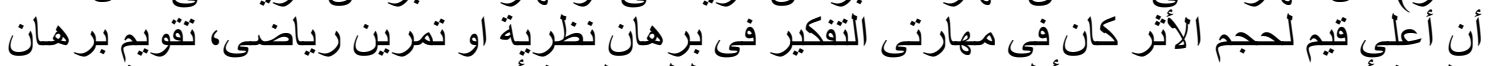

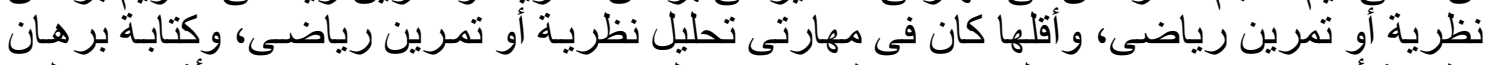

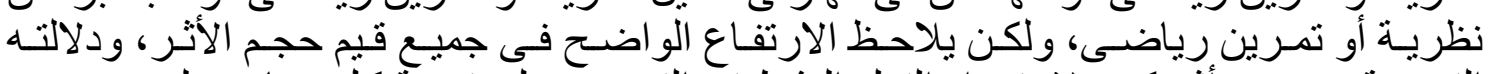

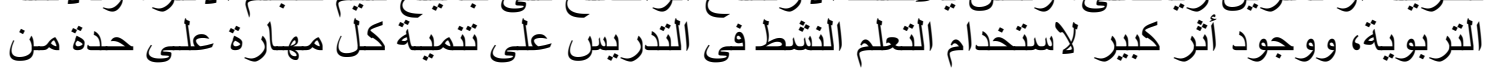


مهار ات البر هان الرياضى، وتنمية مهار ات البر هان الرياضى ككل فى نظريات تشابة المثلثات لدى

جدول (^)

طلاب المجمو عة التجريبية.

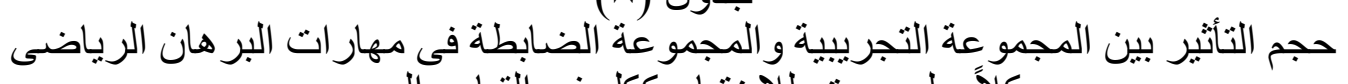

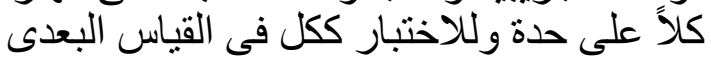

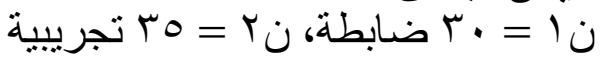

\begin{tabular}{|c|c|c|c|c|c|}
\hline قوة حجنثم & حجم التأثير & قيمة "تلاتلات & دالحرجية & الاختبار ات & b \\
\hline كبيرة &, 0 & $* \Lambda, \mu \tau$ & $7 \pi$ & التحليل & 1 \\
\hline كبيرة &., 19 & $* r, 90$ & $7 \pi$ & التفكير & r \\
\hline كبيرة & $\cdot, Y \wedge$ & $* \xi, V \vee$ & $\pi T$ & الكتابة & $r$ \\
\hline كبيرة & $\cdot, \leqslant Y$ & $* \eta, \wedge 7$ & $\pi r$ & تقويم & $\varepsilon$ \\
\hline كبيرة & $\cdot, \leqslant \leqslant$ & $* V, \cdot V$ & $\pi$ & اختبار البر هان الرياضى ككل & 0 \\
\hline
\end{tabular}

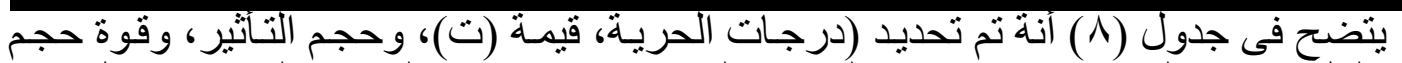

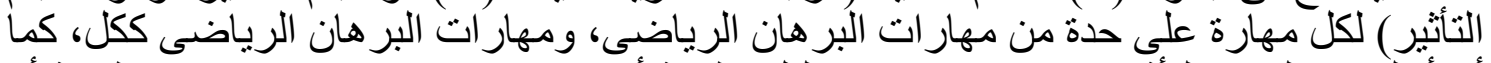

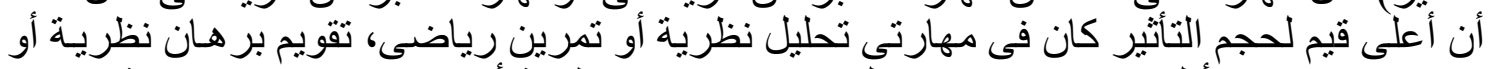

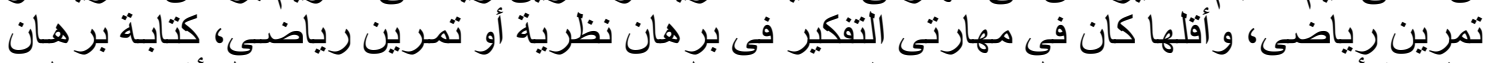

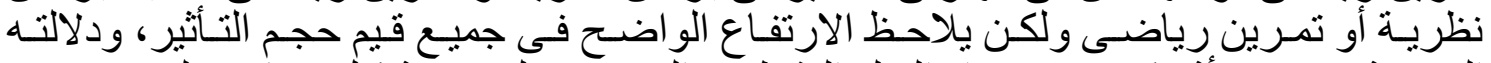

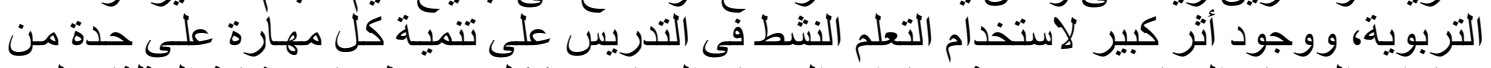

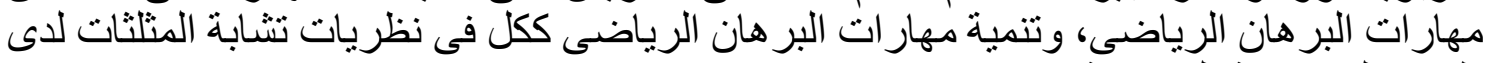
طلاب المجمو عة التجريبية التيانية

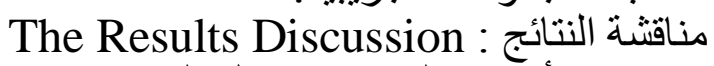

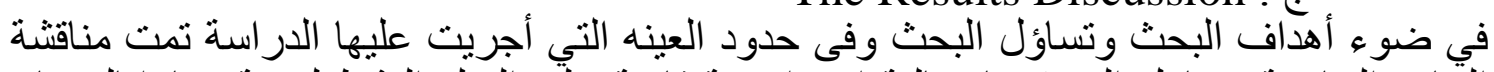

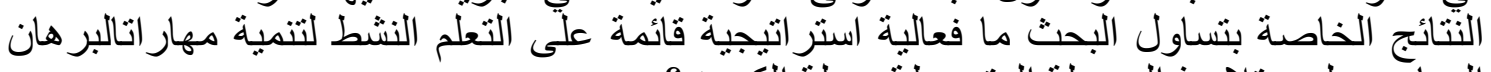

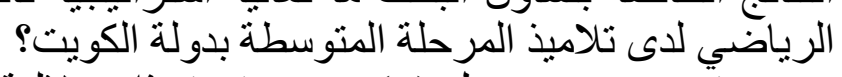

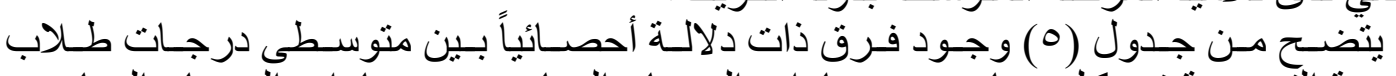

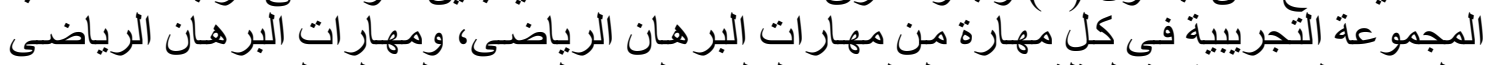

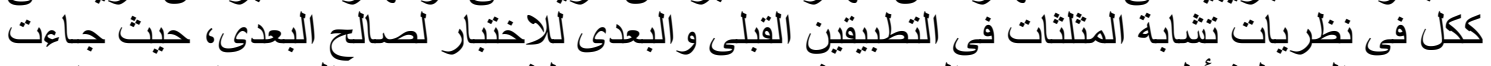

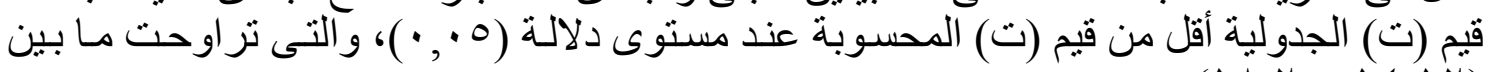

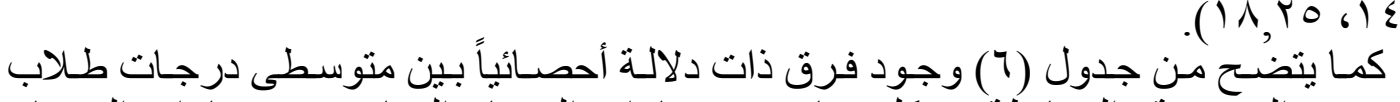

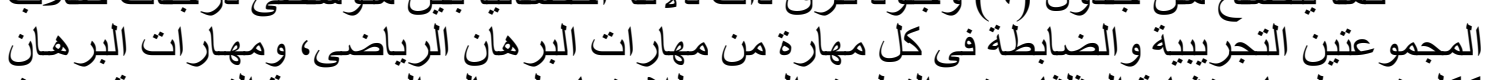

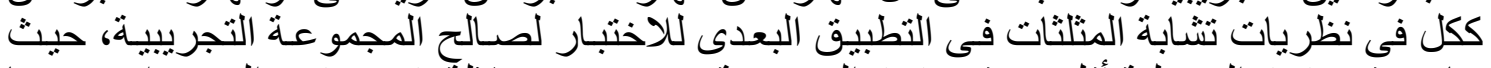

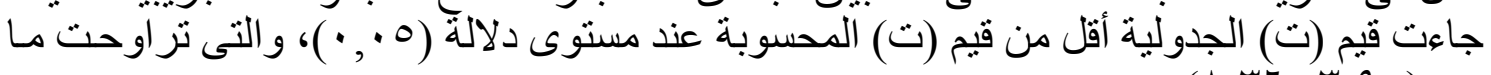

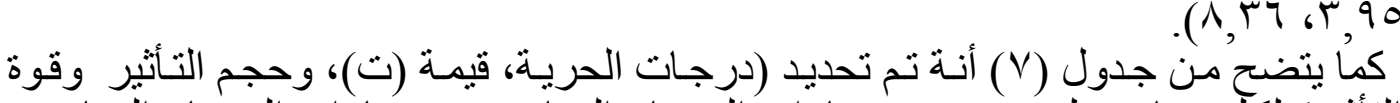

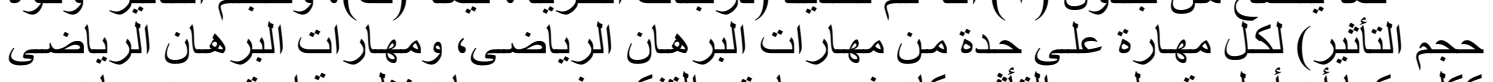

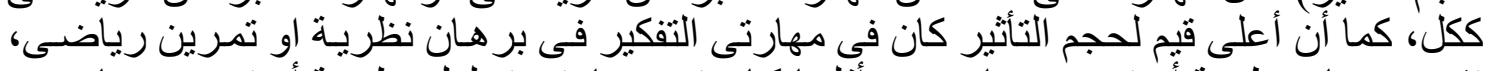

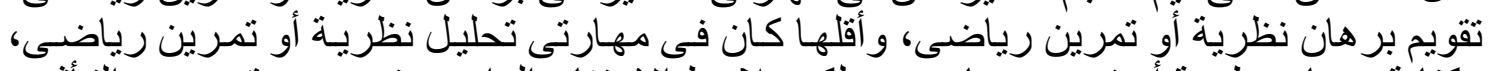

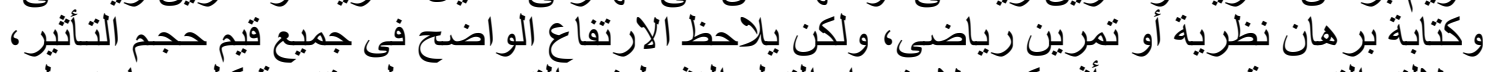

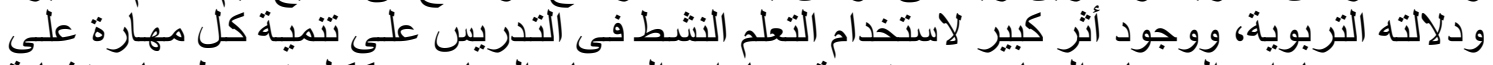

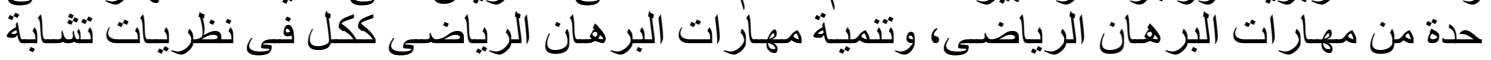
المثلثات لدى طلاب المجمو عة التجريبية. 


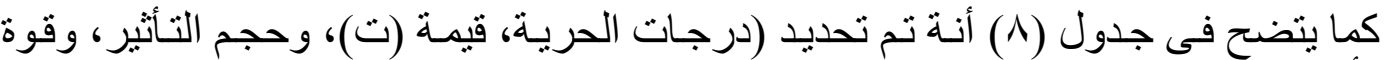

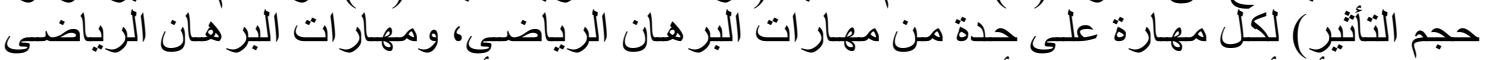

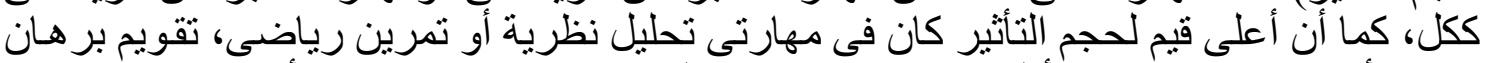

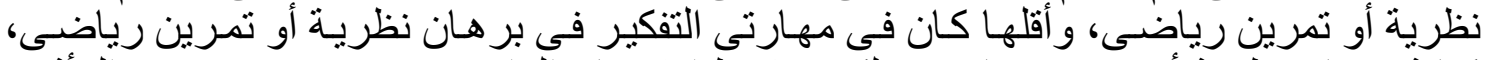

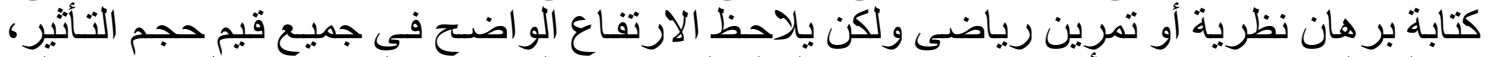

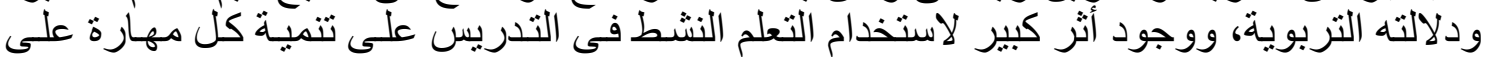

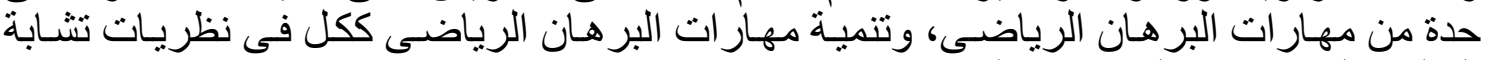
المثلثات لاى طلاب البات المجمو عة التجريبية.

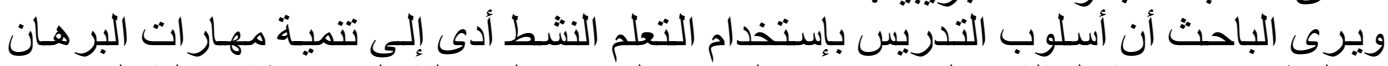

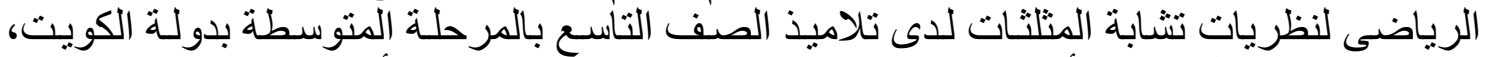

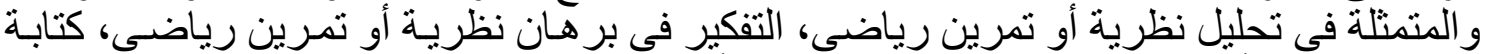

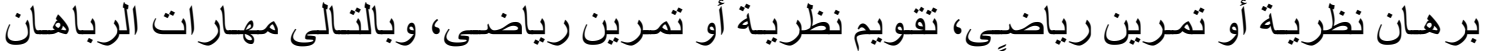

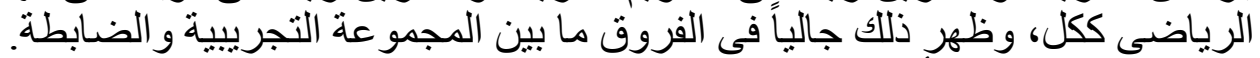

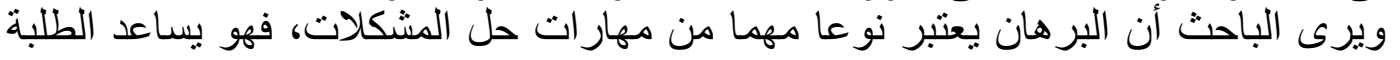

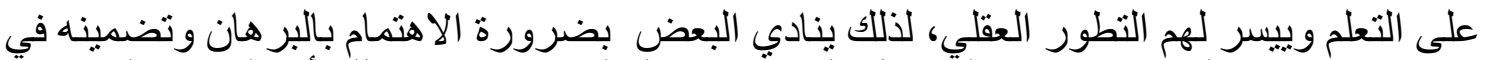

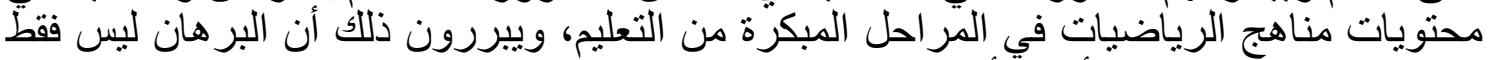

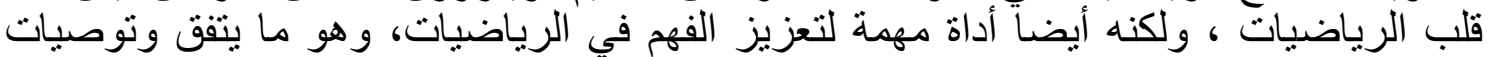

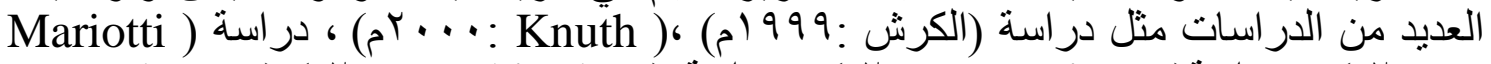

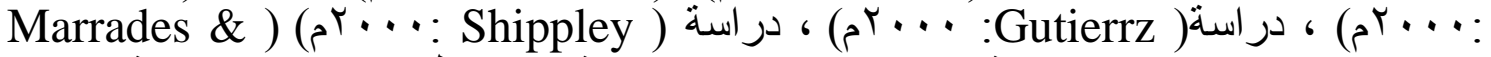
: Gutierrezs

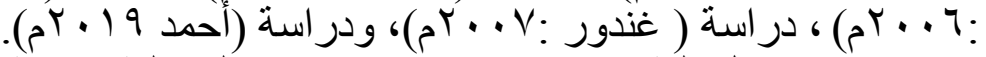

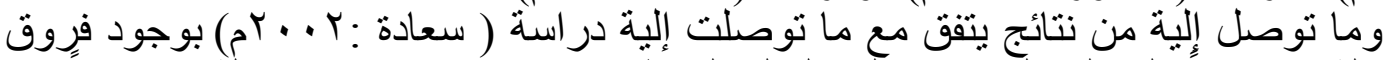

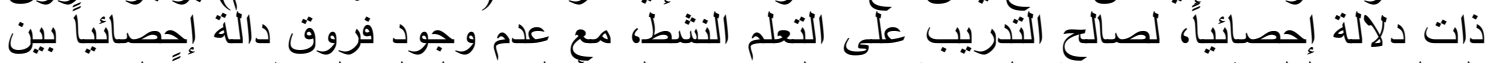

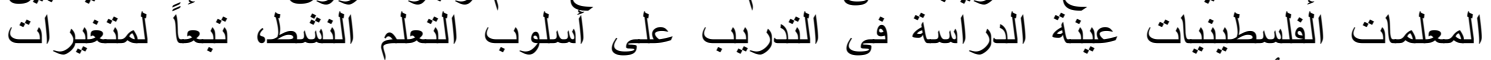

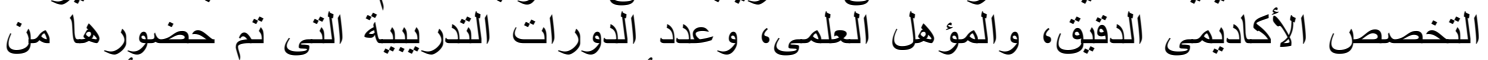

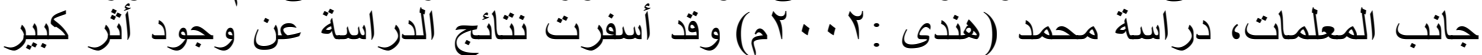

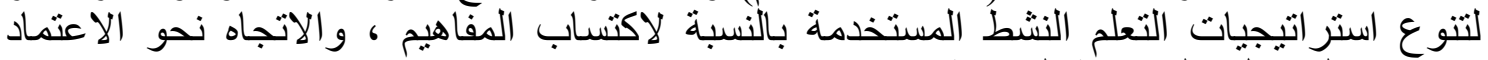

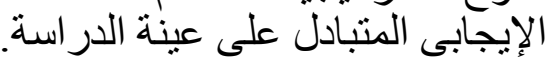

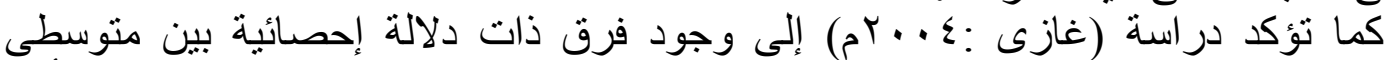

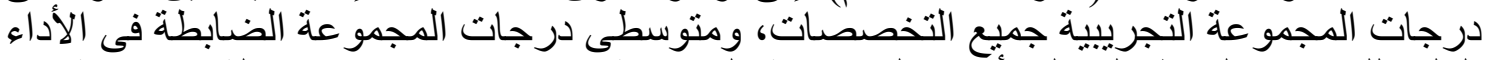

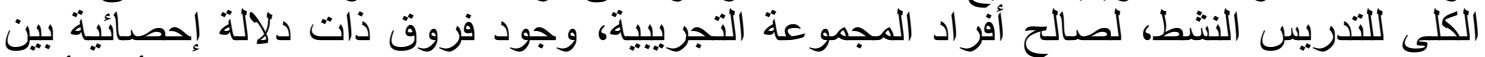

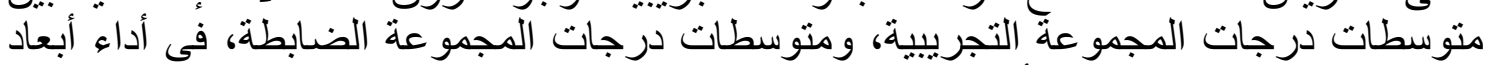

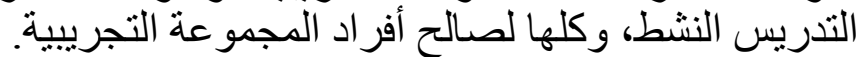

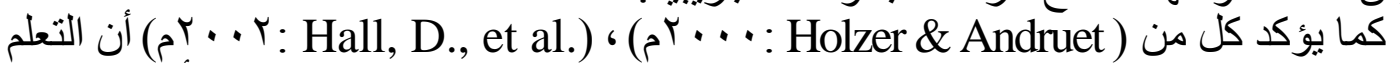

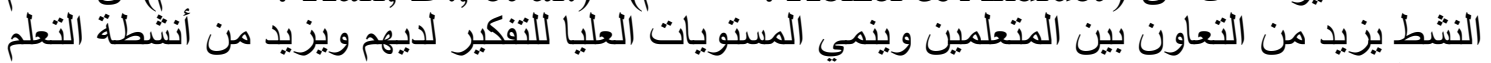

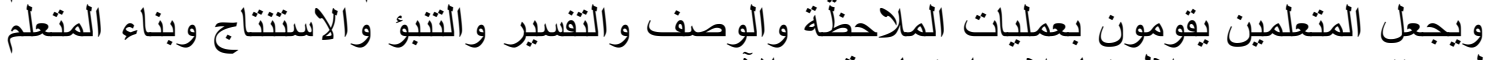

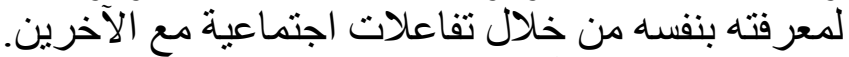
كمـا يـرى كل من (

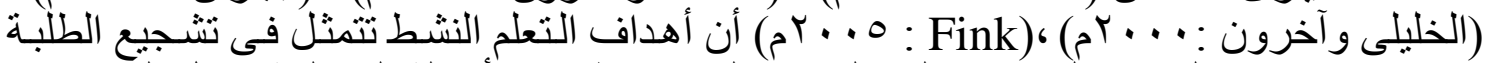

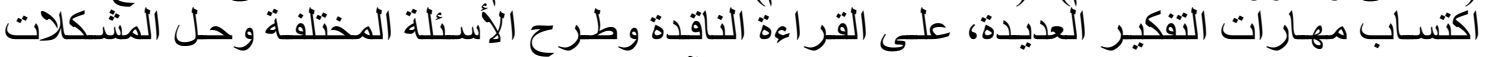

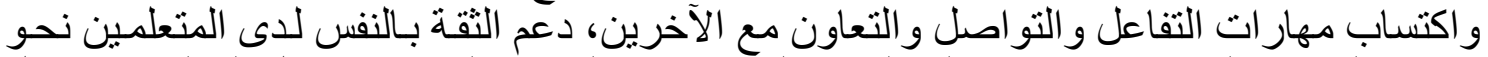

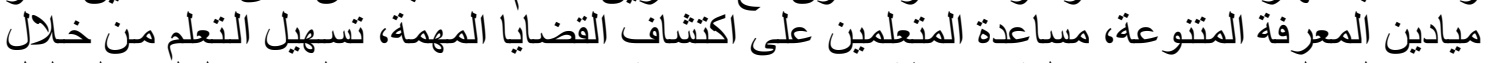
مرور المتعلمين بخبر ات عملية مرتبطة بمشكلات حقيقية، اكتساب مهار ات التفكير التهيات العليا (التحليل 
و التركيب و التقويم) ومهار ات حل المشكلات، وتمكينهم من تطبيقها فى التعلم وفى الحياة، تطوير

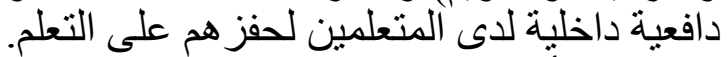

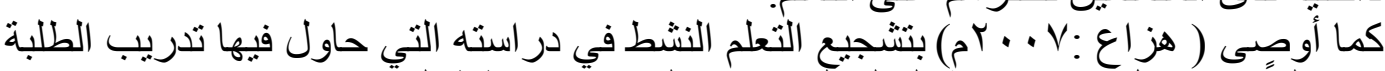

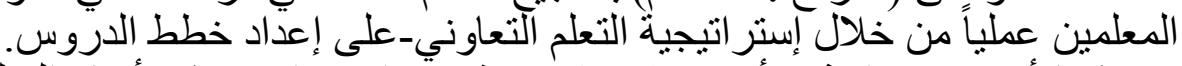

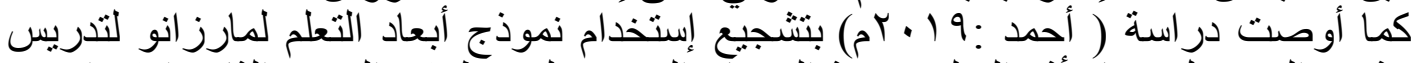

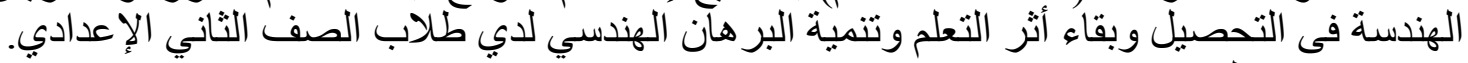

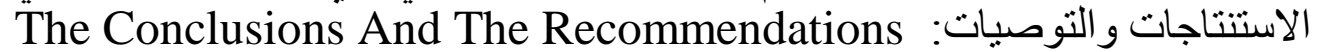

The Conclusions : الاستنتاجات

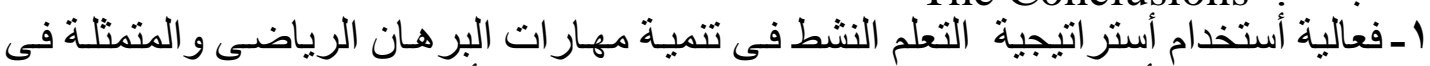

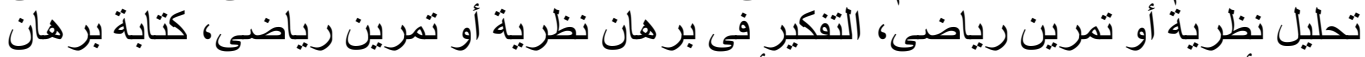

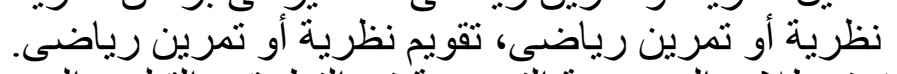

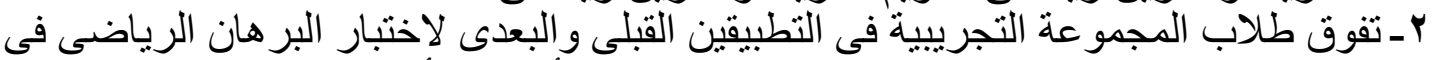

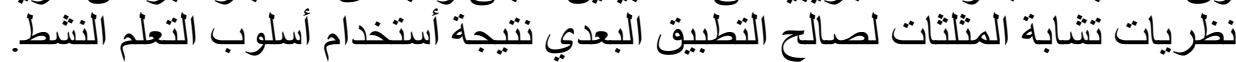

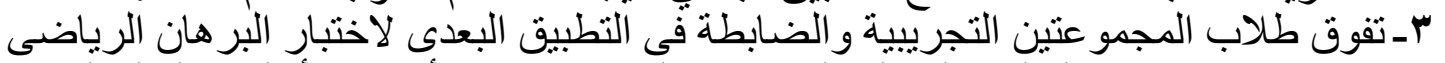

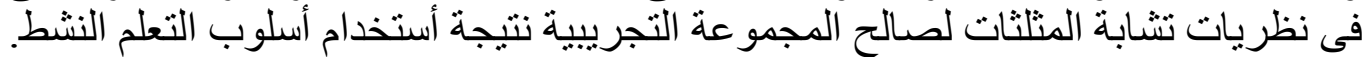

التوصيات : The Recommendations

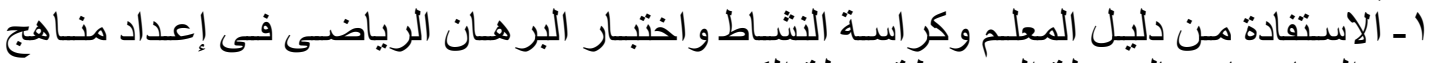

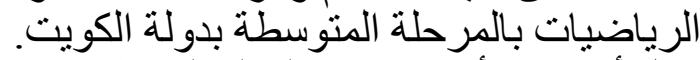

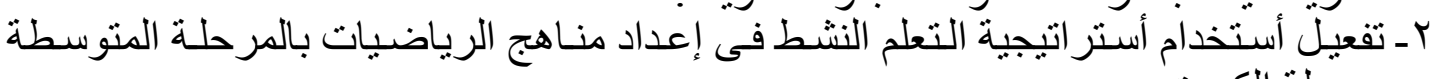

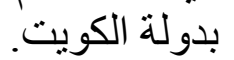

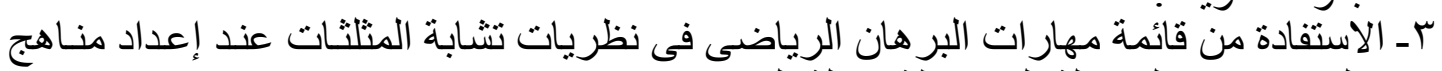

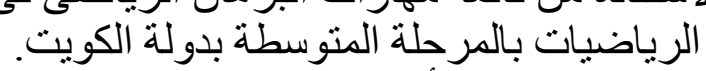

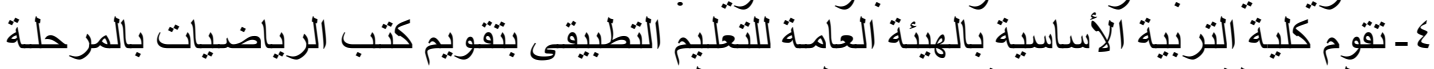

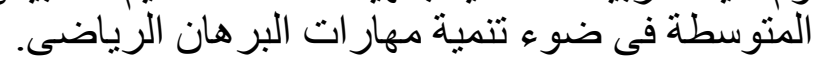

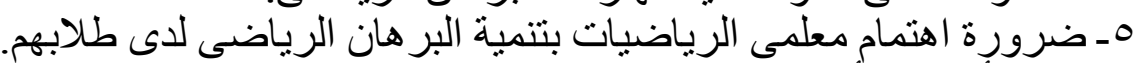

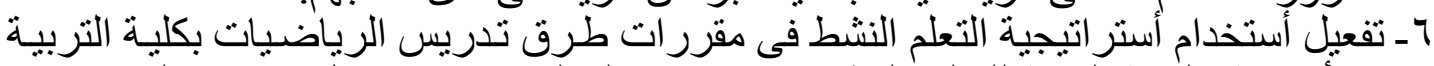

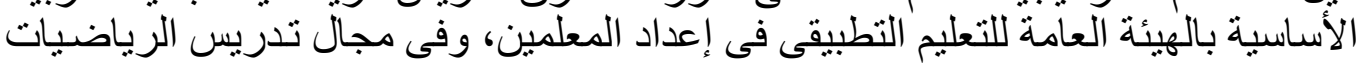

$$
\begin{aligned}
& \text { فى المدارس. } \\
& \text { المر اجع العربية والأجنبية : } \\
& \text { المر اجع العربية: }
\end{aligned}
$$

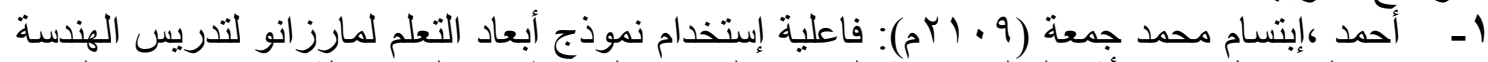

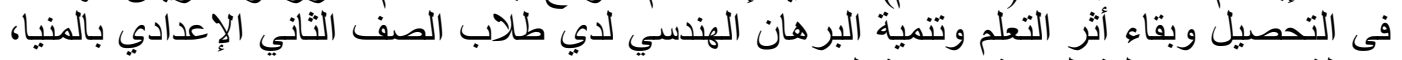

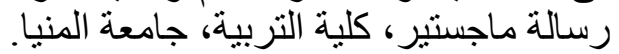

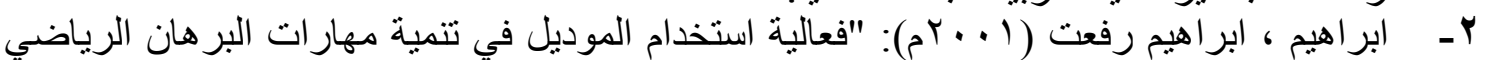

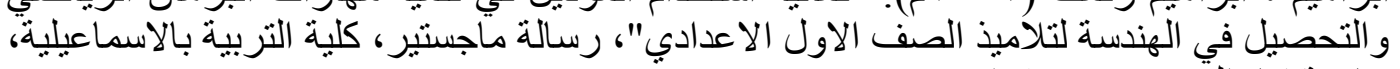

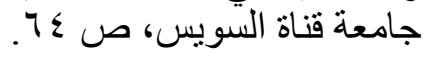

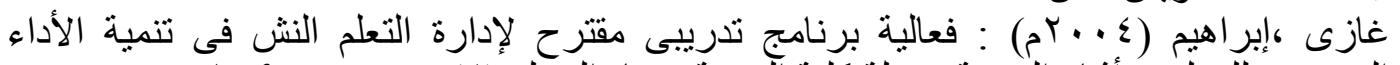

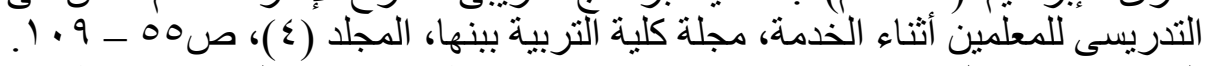

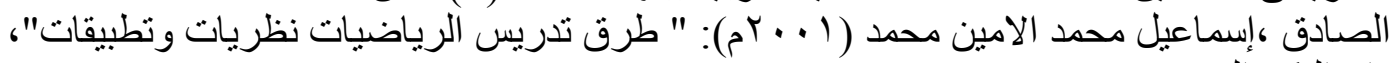
دار الفكر العربي.

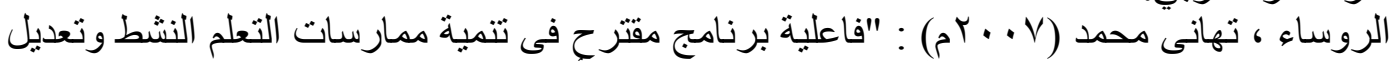

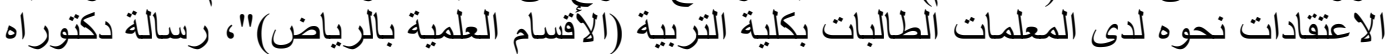
غير منشوره، الرياض، جامعة الرئ الرياض. 


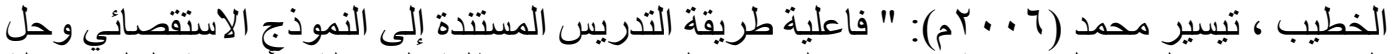

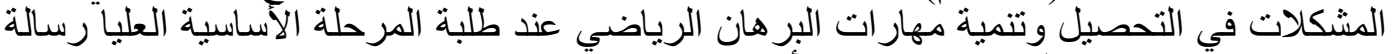

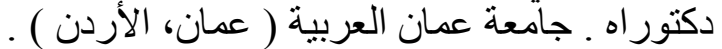

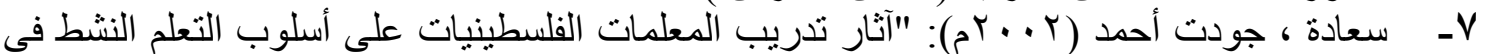

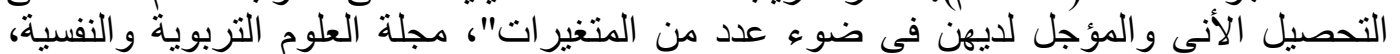

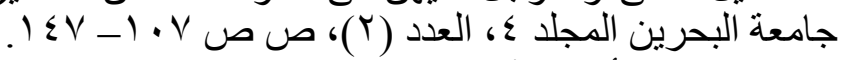

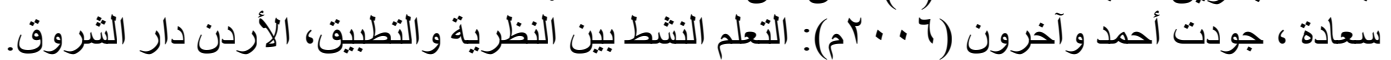

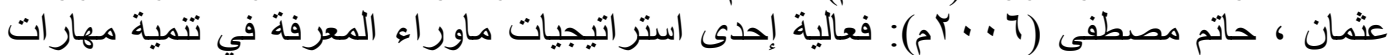

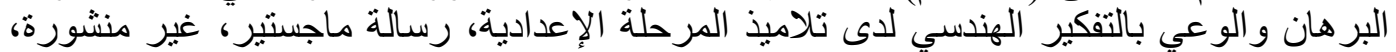

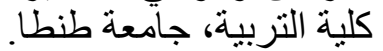
• 1 ـ زيتون ، حسن ، كمال زيتون (r . . rم): التعلم و التدريس من منظور النظرية البنائية، القاهرة، عالم الكتب.

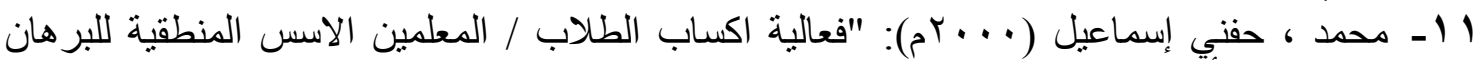

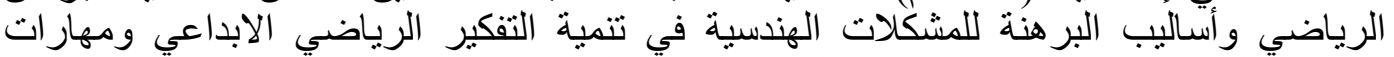

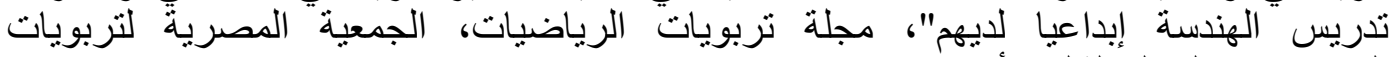

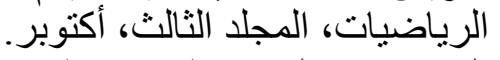

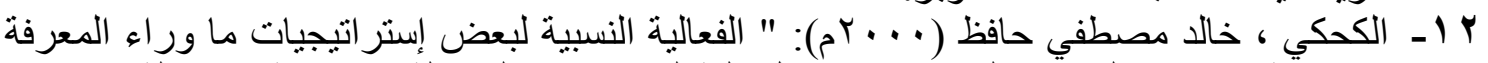
في تتمية مهار ات البرهان الهندسي وإختز ال قلقة لدى تلاميذ المرحلة الإعدادية"، رسالة مالة ماجستير

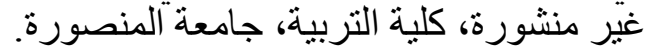

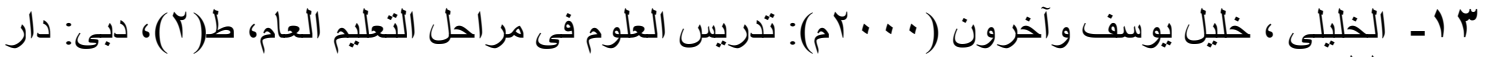

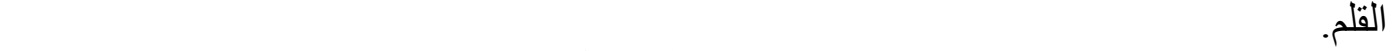

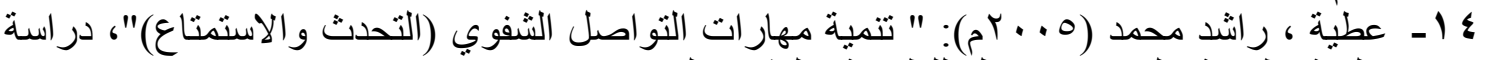

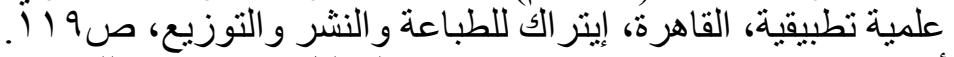

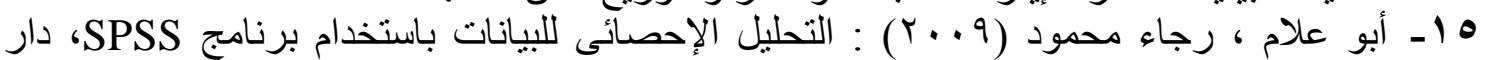

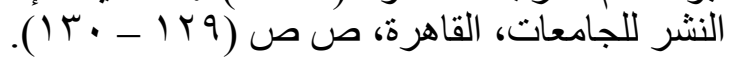

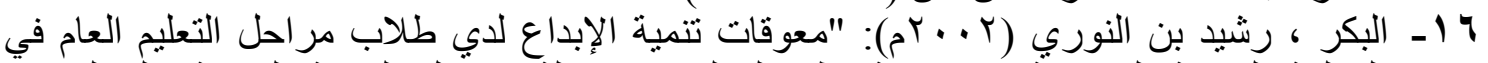

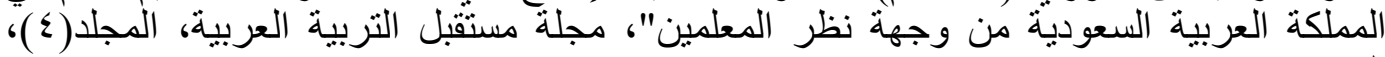

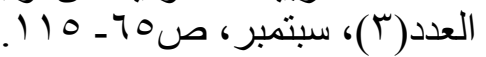
IV

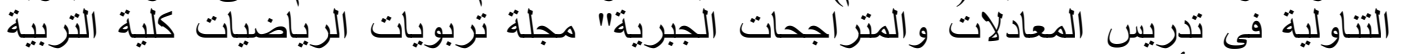

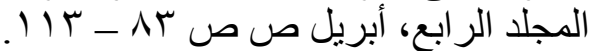

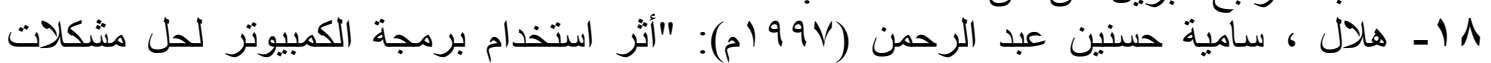
رياضية على التحصيل والتفكير الابتكاري لإى طلى طلاب المرحلة الثانوية، رسالة ماجستير كلية التربية ببنها، جامعة الزفازيق.

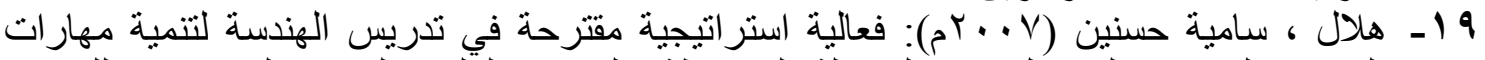

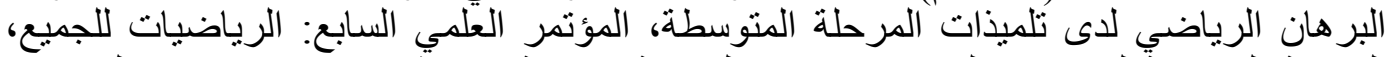

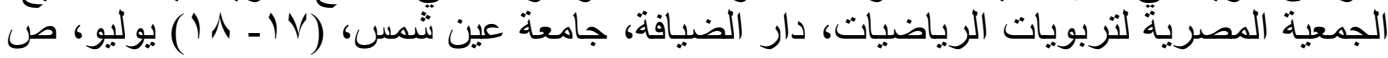
$1 \vee 9-1 \leqslant 9$

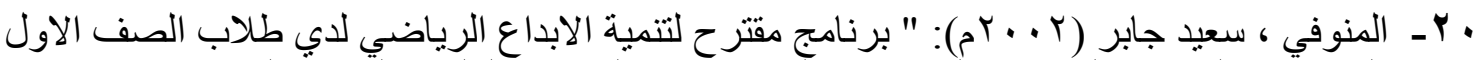

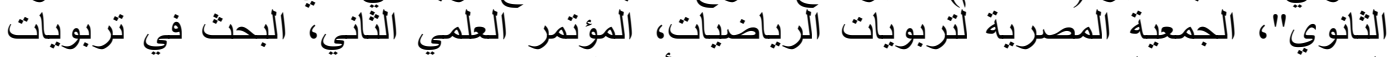

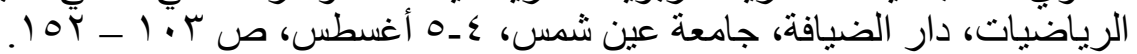

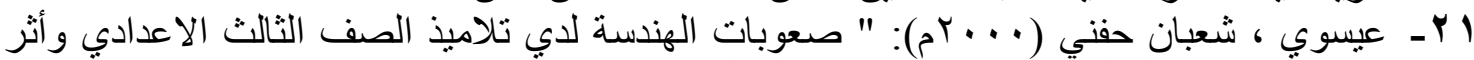

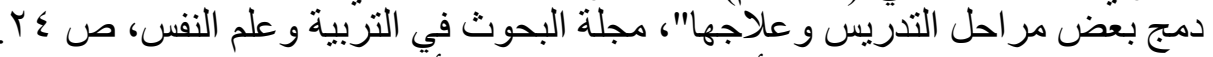

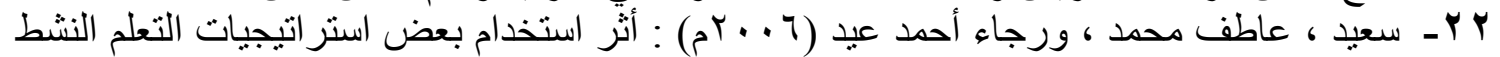

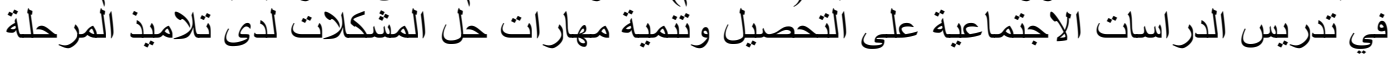


الإعدادية "، مجلة دراسات في المناهج وطرق التدريس، ع |ل||(فبراير)، القاهرة: الجمعية

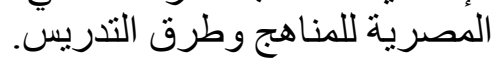

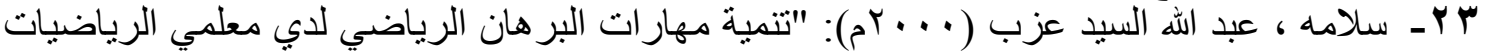

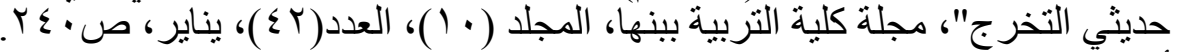

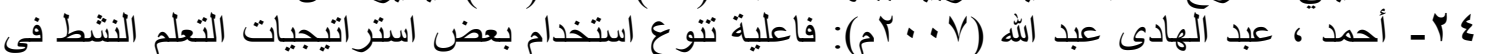

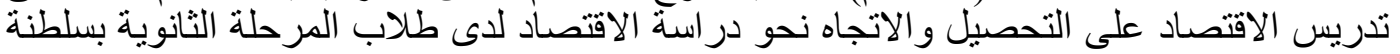

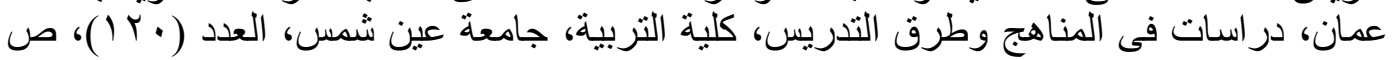

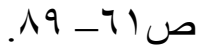

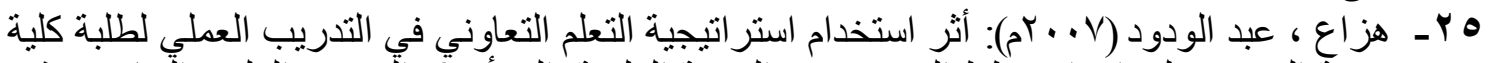

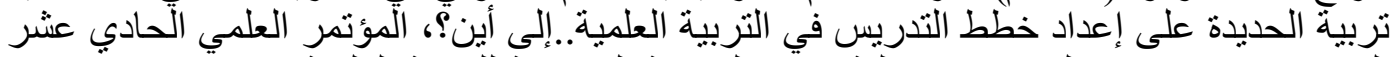

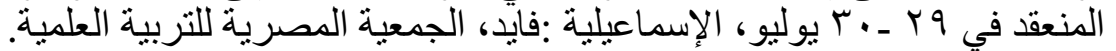

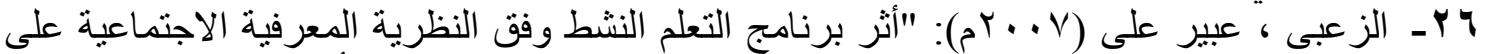

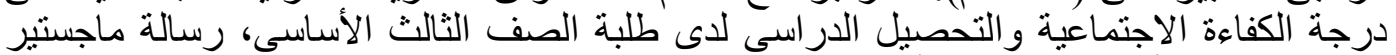
غير منشورة، الأردن، الجامعة الأرداعة الأنية.

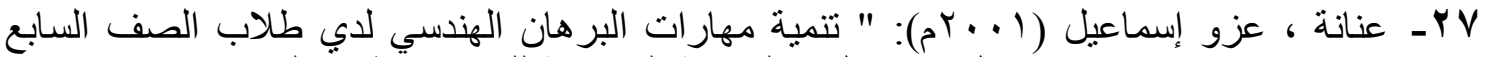

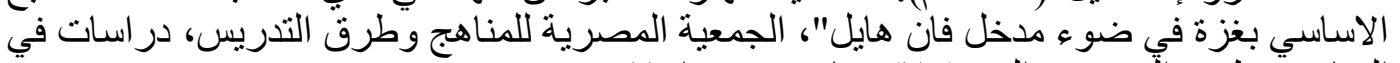

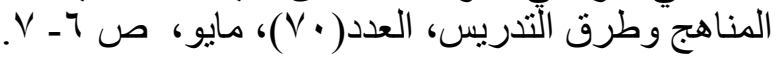

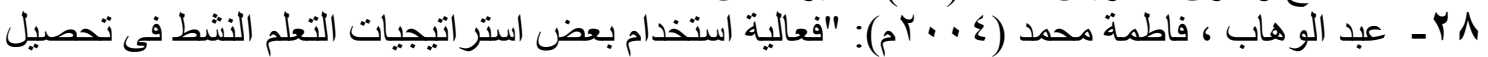

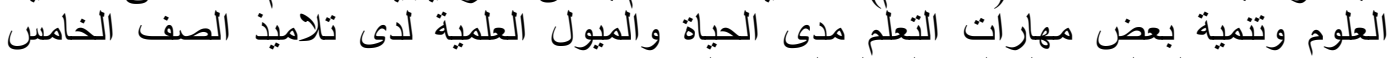

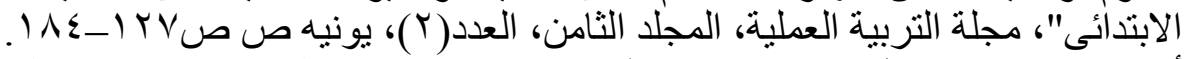

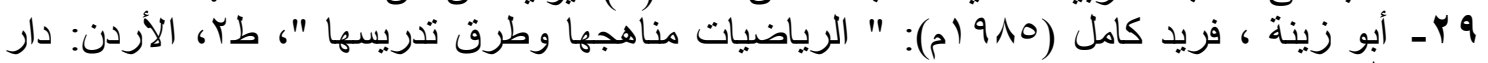

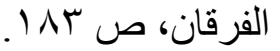

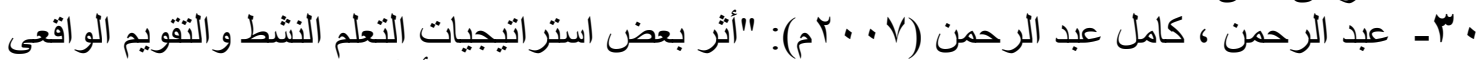

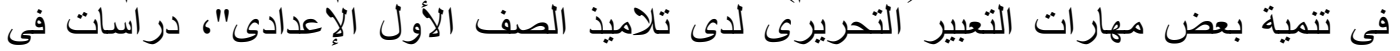

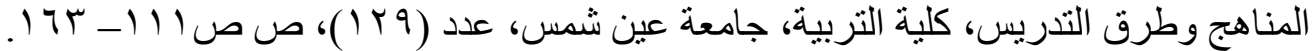

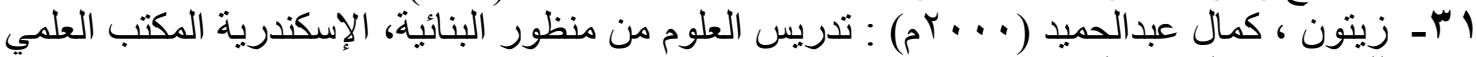

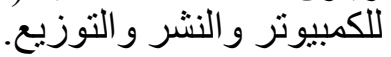

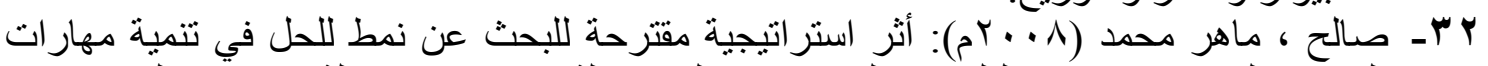

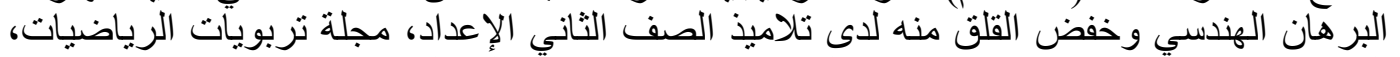

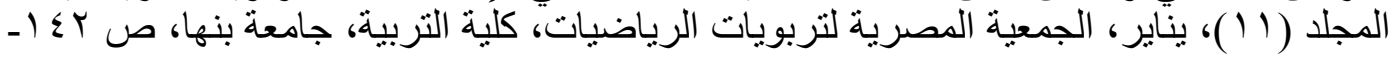
$17 \mathrm{~V}$

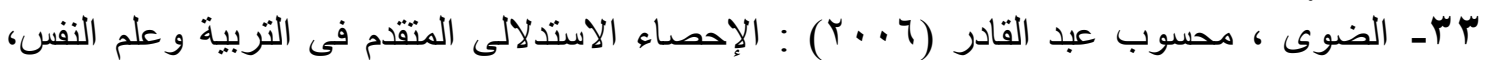

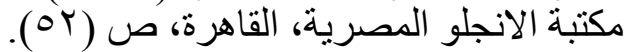

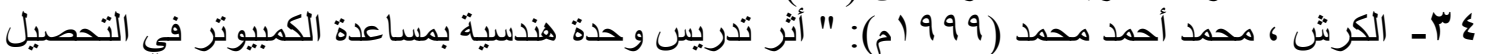

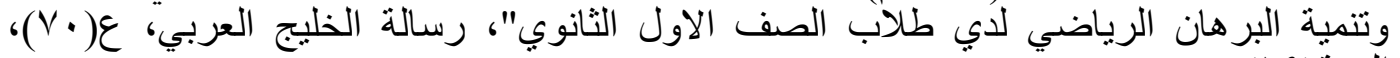

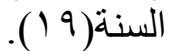

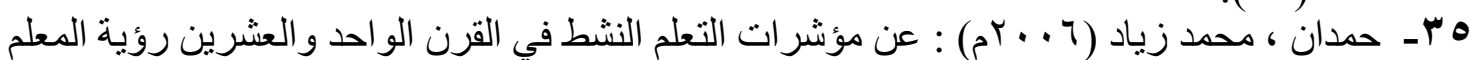

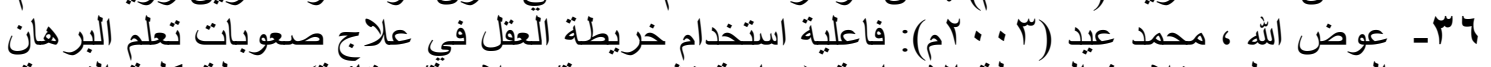

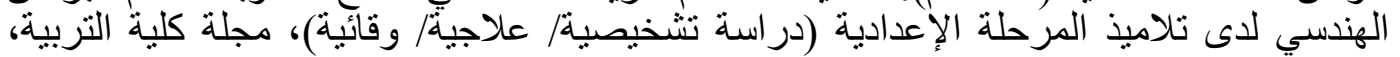

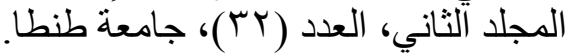

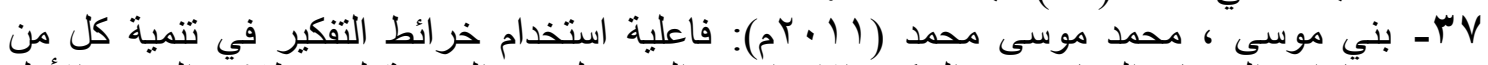

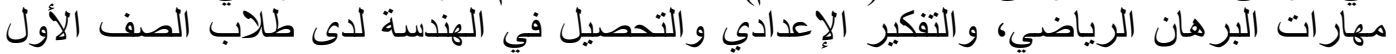

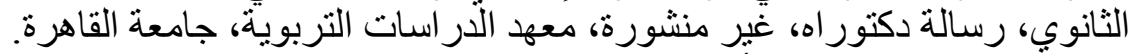

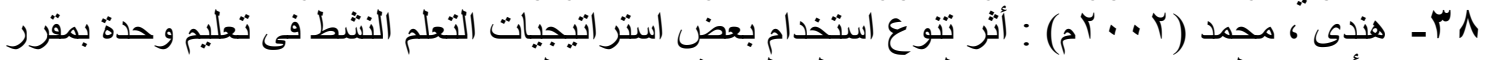
الأحياء على اكتساب بعض المفاهيم البيولوجية وتقدير الذات والاتجات التهاه نحو الاعتماد الإيجابى 


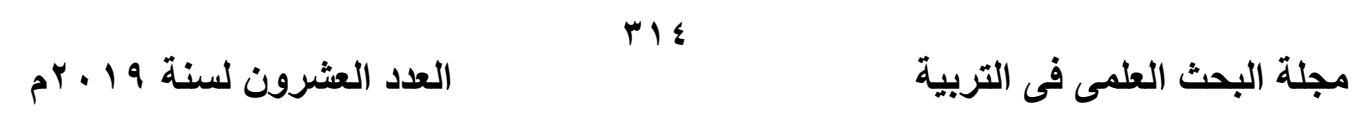

المتبادل لدى طلاب الصف الأول الثانوى الزراعى، مجلة دراسات فى المناهج وطرق التدريس،

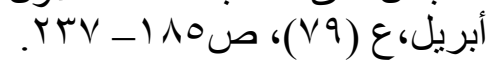

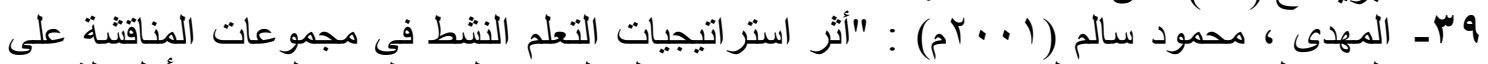

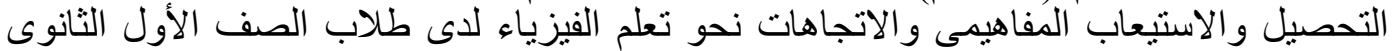

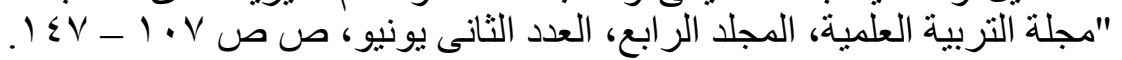

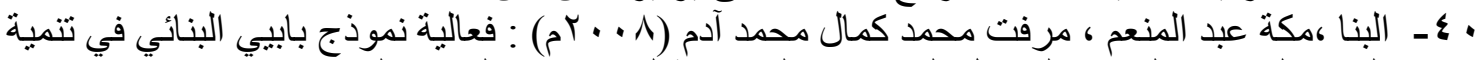

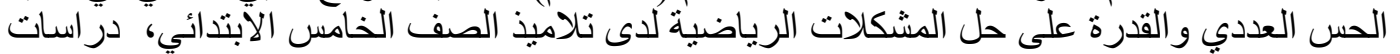

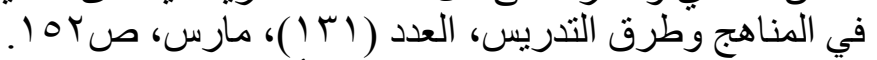

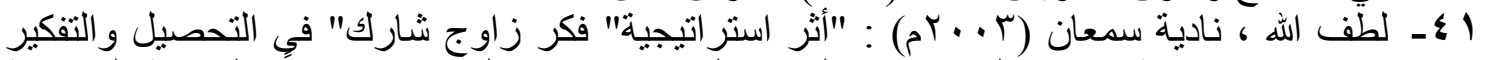

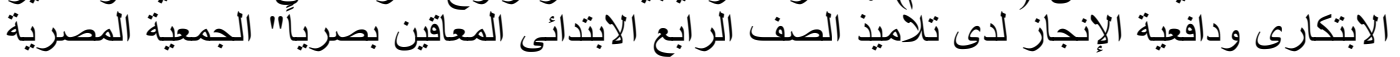

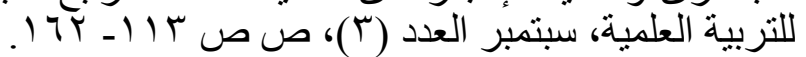

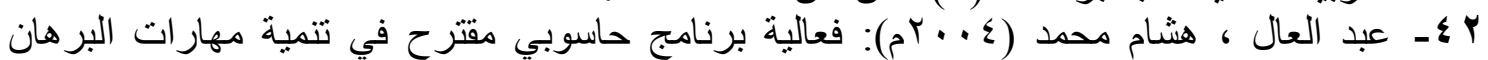

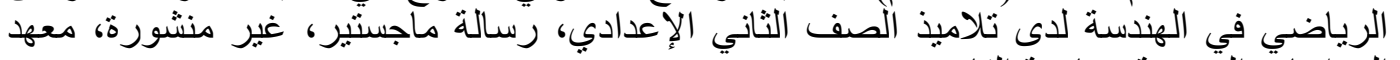

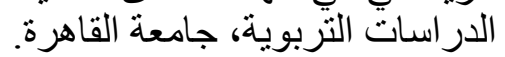

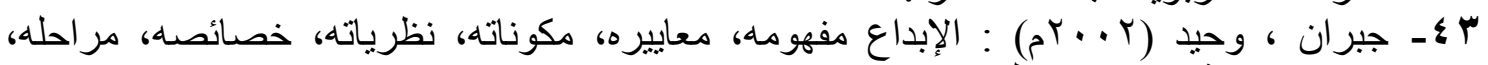

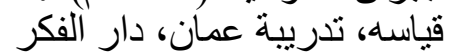

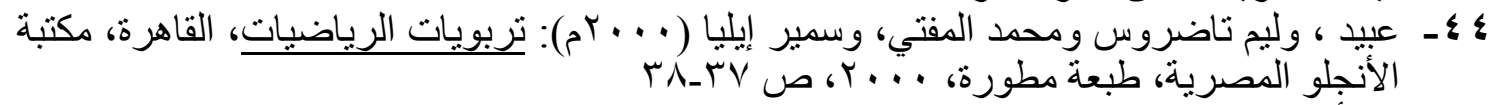

المر اجع الأجنبية : The Foreign References

45-Appelton, Ken (1997): "Analysis and description of students learning during science classes using constructivist - based model", Search in Science Teaching, 3(34).

46-Aldrigo,B(1994): " The Role Of The Mathematics in Scince Education ",J.Of Focus on learning Problem in Maths, PP37.

47-Buffalo Newslatter (1994): Teaching . March "What is Active learning. Vo. III, No. 2. March

48-David, D\& Wilder, S (2003): Learning by Doing in David, P \& others: Learning to teach mathin the secondary school, London, Routledge, PP128.

49-Fink,L Dee (2005): "Integrated course design", Marsh, http://www.idea.kstate.edu/papers/Idea_Paper_42.pdf 9/11/2007.

50-Fox-Cardamone, L. \& Rue, S. (2003): Students Responses to Active learning strategies. An examination to small - group and whole CLASS discuss discussion. Research for education reform, V. 8, N. 3, pp. 3- 15.

51-Hall, S. Watiz, I. Brodeur, D. Nas, R. (2002): Adoptional of active learning in alectrture-based engineering class. ASEE/IEEE Frontiers in Conference. November 6 - , Boston, MA.

52-Hanna,G. ( 2000) : " proof , Explanation and Exploration : An overview " Edu, Stud . in Maths V (44) pp 6- 7.

53-) Henson,K.T. \& Elber,B (1999): Educational psychology for effective teaching wads worth publishing comp, U.S.A:Adivision of International Thomson Pub; Inc

54-Holzer,S.M \& Raul H.Andruet (2000): "Active learning in the classroom", Virginia Polytechnic Institute and State University, Proceedings, SEE Southeastern Section Annual Meeting, Roanoke, VA, Apr pp 2-4.

55-Katz, L. (1994): What should young children be learning. Child care information exchang, 100, No. Dec. 23 - 25. 


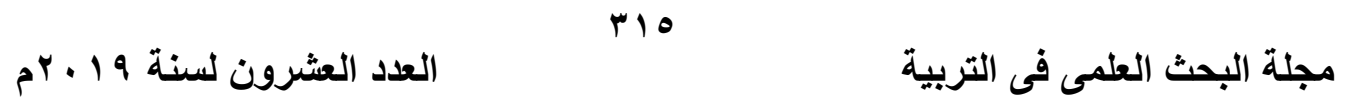

56-Knuth,E,J(2000): "The Nature Of Secondra School Mathematics Teachers, Conceptions Of Proof" D.A.I 60(7), PP ( 3417 - 17 A ).

57-Lee .w . ( 2000 ) :The Relationship Between Students " proof - Writing Ability And Van Hiele Levels of Geometric Through in a College Geometry Course " D.A.I 60(7) June p ( 2417-A)

58-Mariotti,M.A(2000): "Introduction To Proof : The Mediation Of Dynamic Software Environment" Edu. Stud. In Maths . Vol(44) PP(25 -53).

59-Marrades ,R; Gutierrez, A.(2000): "Proofs Produced By Secondary School Student Learning Geometry In Dynamic Computer Environment " Edu. Stud. In Maths . Vol(40) PP(87 -125).

60-McKinney, K. (2001): Active learning. Available at : p. 2 http :// www. cat: istu.edu/teaching-tips/handsout/newactive.Shtml.

61-Shippley,W.J(2000): "An Investigation Of College Students, Understanding Of Proof Construction When Doing Mathematical Analysis Proof " D.A.I 60(7)Jan. PP(2417.A). 
